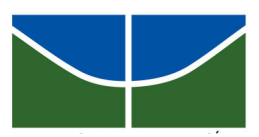

UNIVERSIDADE DE BRASÍLIA

Centro de Excelência em Turismo

Pós-graduação Lato Sensu

Curso de Especialização em Hotelaria Hospitalar

\title{
Padronização de Serviços a partir da Estrutura Organizacional de uma Instituição de Saúde utilizando Indicadores da Hotelaria Tradicional Caso: Hospital Santa Lúcia
}

Andréa Borba Gurgel do Amaral de Carvalho

McS Ariádne Bittencourt

Brasília - 2009 


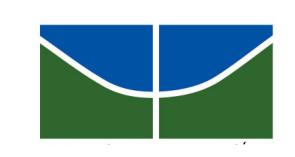

UNIVERSIDADE DE BRASÍLIA

Centro de Excelência em Turismo

Pós-graduação Lato Sensu

Curso de Especialização em Hotelaria Hospitalar

\section{Padronização de Serviços a partir da Estrutura Organizacional de uma Instituição de Saúde utilizando Indicadores da Hotelaria Tradicional Caso: Hospital Santa Lúcia}

Andréa Borba Gurgel do Amaral de Carvalho

McS Ariádne Bittencourt

Monografia apresentada ao Centro de Excelência em Turismo - CET, da Universidade de Brasília - UnB, como requisito parcial à obtenção do grau de Especialista em Hotelaria Hospitalar.

Brasília - 2009 


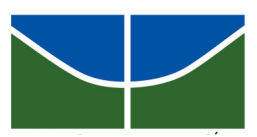

UNIVERSIDADE DE BRASÍLIA

Centro de Excelência em Turismo

Pós-graduação Lato Sensu

Curso de Especialização em Hotelaria Hospitalar

\section{Andréa Borba Gurgel do Amaral de Carvalho}

Aprovado por:

Professora orientadora: MSc Ariádne Bittencourt

Professora: MSc Ana Rosa D. Santos

Professora: MSc Shirley Pontes

Brasília, 09 de setembro de 2009. 


\section{AGRADECIMENTOS}

Agradeço primeiramente a Deus por me dar forças e saúde para essa jornada, ao meu esposo Luís Carlos pelo incentivo e paciência, aos meus filhos André Luís e Alex pelas alegrias dos seus sorrisos, a minha orientadora Ariadne pela compreensão nas minhas dificuldades, aos familiares e amigos pela caminhada. 


\section{RESUMO}

O presente estudo teve como objetivo identificar e elencar a estrutura organizacional de uma instituição de saúde e comparar com a padronização dos serviços utilizando os indicadores da hotelaria tradicional para buscar a qualidade esperada. Para o desenvolvimento do arcabouço teórico se fez necessário abordar questões sobre os meios de hospedagem, hotelaria tradicional, hotelaria hospitalar, indicadores, padronização, entre outros. A metodologia da pesquisa foi exploratória utilizando-se do método observacional no setor habitacional do hospital Santa Lúcia, fazendo uso da matriz de classificação da hotelaria hospitalar para trazer a luz do desenho os indicadores e o esboço de uma estrutura organizacional mínima que indique possibilidades de adoção de um padrão de serviços. 


\begin{abstract}
This study aimed to identify and rank the organizational structure of a health institution from the standardization of services by using the indicators of traditional hotels as a factor resulting quality. To develop the theoretical framework was necessary to address questions about the means of accommodation, traditional hotels, hospital stays, indicators, standardization, among others. The research methodology was exploratory using the observational method in the housing sector of the hospital Saint Lucia, using the classification matrix of hospital stays to bring the light of the indicators and drawing outline of an organizational structure that indicates the minimum possibilities of adopting a standard of service.
\end{abstract}




\section{SUMÁRIO}

\begin{tabular}{|c|c|}
\hline \multicolumn{2}{|c|}{ INTRODUÇÃO } \\
\hline 1 & MEIOS DE HOSPEDAGEM............... \\
\hline 1.1 & HOTEL ...................... \\
\hline 1.1.1 & SISTEMA DE CLASSIFICAÇÃO DOS MEIOS DE HOSPEDAGEM .... \\
\hline 1.2 & HOSPITAL ............. \\
\hline 1.2 .1 & ACREDITAÇÃO.... \\
\hline 2 & HOTELARIA HOSPITALAR..... \\
\hline 2.1 & 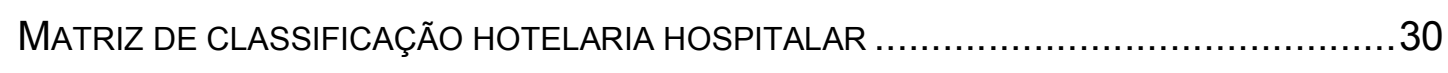 \\
\hline 2.2 & SERVIÇOS COMPATIVEIS ......... \\
\hline 3 & PADRONIZAÇÃO................. \\
\hline 4 & INDICADORES............ \\
\hline 5 & QUALIDADE ................ \\
\hline 5.1 & 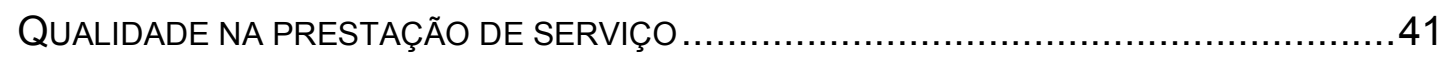 \\
\hline 6 & DESCRIÇÃO DO ESTUDO ........................ \\
\hline 6.1 & HOSPITAL SANTA LÚCIA .... \\
\hline 7 & METODOLOGIA \\
\hline 8 & APRESENTAÇÃO E ANÁLISE DE RESULTADOS \\
\hline 9 & 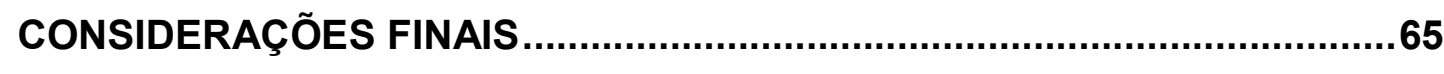 \\
\hline 10 & REFERÊNCIAS .................................. \\
\hline 11 & APÊNDICE ................... \\
\hline
\end{tabular}




\section{INTRODUÇÃO}

O presente trabalho tem como identificar e elencar a estrutura organizacional de uma instituição de saúde e comparar com a padronização dos serviços utilizando os indicadores da hotelaria tradicional para buscar a qualidade esperada. O tema foi delimitado buscando o dimensionamento da estrutura orgânica da instituição de saúde privada: o Hospital Santa Lúcia, em Brasília /DF, a partir de indicadores e da padronização para os serviços prestados.

A problemática deste estudo se constituiu a partir da observação in loco no ambiente hospitalar. Identifica-se ainda uma precariedade na adoção de uma estrutura padronizada de áreas/setores em que se visualizem atividades vinculadas a Hotelaria. Buscou-se, então, o seguinte questionamento: Como dimensionar a estrutura organizacional de uma instituição de saúde a partir dos indicadores e da padronização da hotelaria tradicional?

Os objetivos específicos foram construídos estabelecendo uma abertura que permitisse responder a problemática em questão. Identificar a estrutura organizacional das instituições de saúde privada versus hotelaria tradicional para fins de aproximar as similaridades das áreas/setores; Identificar as áreas/serviços da hotelaria tradicional como possibilidade de traçar indicadores e possível padronização para hotelaria hospitalar; Selecionar os indicadores prioritários da hotelaria tradicional que possam levar a padronização na hotelaria hospitalar. 
$\mathrm{Na}$ hotelaria tradicional percebe-se que existe uma grande interlocução entre os setores macro, sendo esses possíveis de serem adaptados para a hotelaria hospitalar como: Segurança; Saúde Higiene; Conservação/Manutenção; Atendimento ao Cliente; Portaria e Recepção; Acessos e Circulações; Setor Habitacional; entre outros.

Os setores acima citados estão totalmente interligados favorecendo um atendimento diferenciado com qualidade aos clientes. Este é o princípio defendido na hospitalidade, segundo Gogoi(2004, 41), a mesma pode e reduz radicalmente o sofrimento de pacientes e clientes, minimizando a dor para pacientes e familiares de dor e fragilidade, premissa defendida na hotelaria e que se faz necessário em um ambiente hospitalar. A partir deste princípio buscamos compreender a estrutura organizacional de uma unidade de saúde e estabelecer esta relação na hotelaria hospitalar.

A hotelaria hospitalar surgiu nos hospitais para minimizar o desconforto desses ambientes, até então "frios e impessoais", projetando ambientes de descanso, tranqüilidade e relaxamento, permitindo aos clientes confiança e condições de uma recuperação mais rápida e, por sua vez, propiciando aos profissionais um ambiente de trabalho que possibilite um atendimento de melhor qualidade (Tarabolsi, 2006).

Esta tendência busca transformar ambientes e processos operacionais agregando mais qualidade para a instituição, maior preocupação em oferecer um serviço diferenciado para atender melhor ao cliente de saúde, desde a recepção, serviço de quarto, higiene, lavanderia, e até mesmo nas mudanças do ambiente, propriamente, na decoração e na arquitetura. Para funcionar no padrão hoje adotado 
pela hotelaria tradicional, há necessidade de adoção de indicadores que levem ao uma padronização dos serviços, especialmente na área de hospedagem, no setor da governança, foco desta pesquisa. E para que isso ocorra a instituição deve ter uma estrutura organizacional que the permita uma interlocução e agilidade na operação e gestão. O que se observa é que ainda é muito tímida a estrutura organizacional da hotelaria hospitalar nas unidades de saúde.

A pesquisa desenvolvida foi exploratória e documental, fazendo uso do método observacional para aplicação da matriz de classificação adaptada à hotelaria hospitalar no setor de hospedagem do hospital privado Santa Lúcia, mas especificamente no setor da governança. A análise foi feita a partir da matriz de classificação da hotelaria hospitalar, verificando os indicadores dos padrões de serviços e produtos de um Meio de Hospedagem - unidade habitacional de saúde.

Os capítulos foram estruturados a partir dos itens e subitens, descritos como: Meios de hospedagem; Hotel; Sistema de classificação dos meios de hospedagem; Hospital; Acreditação; Hotelaria hospitalar; Matriz de classificação hotelaria hospitalar, Serviços compatíveis, Padronização, Indicadores, Qualidade; Qualidade na prestação de serviços; e a descrição do estudo no Hospital Santa Lúcia. 


\section{MEIOS DE HOSPEDAGEM}

Os meios de hospedagem são estabelecimentos licenciado pelas autoridades competentes onde prestam serviços de hospedagem, os mesmos são administrados por empresa hoteleira, atendendo e mantendo padrões classificatórios previstos pela legislação.

"Os meios de hospedagem, atualmente, fazem parte de uma grande indústria, a denominada indústria da hospitalidade". Essa é muito diversificada e explora diversos ramos de atividades: " (Longanese, 2004:19)

A hospedagem, segundo Longanese (2004), conceitua-se por ser um edifício ou prédio contendo basicamente unidades habitacionais, uma recepção e uma governança. Podendo ter na estrutura, alimentos e bebidas, compreendido de adega, restaurante, bar, cantina e despensa; e ainda ter um estacionamento externo, garagem interna e área de lazer.

De acordo com o Instituto Brasileiro de Turismo - Embratur, por meio da deliberação normativa $n^{\circ} 433$, de 30 de dezembro de 2002, estabeleceu-se que os meios de hospedagem deverão oferecer aos hóspedes no mínimo: uma recepção para atender e controlar a entrada e saída; guarda de bagagem e objetos de uso pessoal dos hóspedes, em local apropriado; conservação, manutenção e arrumação e limpeza das áreas, instalações e equipamentos. Langanese enfatiza os padrões comuns fixados no artigo $7^{\circ}$ do Regulamento Geral dos Meios de Hospedagem, e segundo esse Regulamento a UH é o espaço destinado à utilização pelos hóspedes para o uso de higiene, descanso e conforto, essas UH'S dividem-se em: quarto; apartamento e suíte. 
Uma empresa hoteleira pode ser entendida como sendo uma organização que, mediante o pagamento de diárias, oferece alojamento à clientela indiscriminada. (Castelli, 2001).

De acordo com Petrocchi (2002: 46) “A organização da empresa hoteleira ocorre mediante a dimensão de instalações, dos recursos humanos e equipamentos, necessários para o funcionamento como também a divisão racional de trabalho por criação de órgãos e postos de trabalho".

Já para Longanese (2004:20) “Empresa hoteleira é a pessoa jurídica, constituída na forma de sociedade anônima ou sociedade por cotas de responsabilidade limitada, que explore ou administre meios de hospedagem e que tenha em seus objetivos sociais o exercício de atividade hoteleira".

"As empresas hoteleiras são organismos econômicos que combinam os fatores natureza, capital e trabalho na produção e circulação de seus produtos e serviços" (Duarte, 1996: 32) com isso empresa individual, sociedade por cotas limitadas ou sociedade anônima, e a sociedade em conta de participação compõe essa segmentação de mercado.

A classificação dos meios de hospedagem, criada no Brasil pelo EMBRATUR (1995), oficialmente se divide em vários tipos de categorias: Luxo Superior, Luxo, Standard Superior, Standard e Simples, identificados pela pontuação definida pela aparência da construção, dos seus equipamentos, pela qualidade variada de serviços prestados; o símbolo identificador é o número de estrelas, sendo as mesmas atribuídas por tipos de equipamentos, instalações físicas e qualidade nos serviços.

Destaca-se neste estudo o meio de hospedagem o hotel tradicional e sua interface com o hospital, focando a padronização na qualidade dos serviços prestados. 


\subsection{HOTEL}

Conceitua-se hotel como uma unidade completa reunindo em si requisitos necessários como quarto privativo com alimentação onde o cliente possa desfrutar tranqüila e despreocupadamente as suas necessidades. Castelli (2002).

"Os hotéis são descritos como negócios de hospitalidade comercial, exercem um importante papel em muitas economias e sociedades onde operam", para Ingram (2002: 13).

No ponto de vista de Longanese (2004: 40). “Hotéis são organizações de prestações de serviços, os quais alugam parte de suas dependências às pessoas ou organizações, por um determinado período de tempo. O principal produto do hotel é a unidade habitacional podendo ser um simples quarto, um luxo ou ainda uma suíte".

E segundo Castelli (2001), O hotel pode ser visto como um sistema, como a figura abaixo mostra, composta de vários subsistemas ou áreas, e cada uma dessas áreas podem sofrer uma divisão ainda maior. É o caso da área de hospedagem, que se compõe de recepção, telefonia e governança. Essas áreas são denominadas de Unidades Gerenciais Básicas - UGBs, e é no interior de cada uma delas que as pessoas executam suas tarefas ou realizam as suas atividades. 
Figura 1. Sistema Hotel

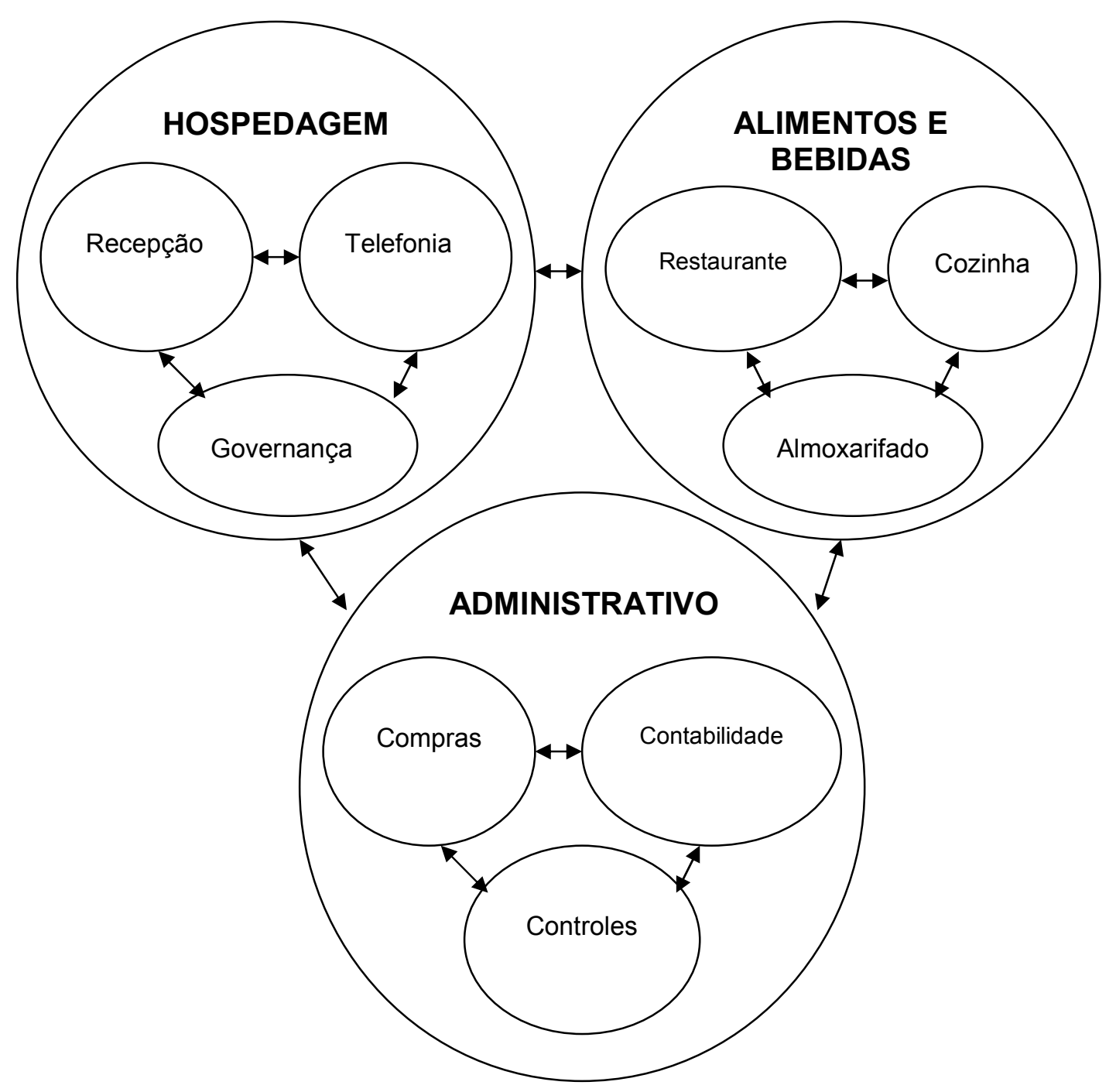

Fonte: Castelli $(2001,81)$

De acordo com Marques (2003:28) em um hotel, a grande preocupação dos responsáveis deve ser manter o nível e a qualidade dos serviços prestados. 
Para que isso ocorra de forma eficaz o empreendedor, de acordo com Petrocchi (2002: 47), deve englobar o planejamento do hotel da seguinte maneira:

- estrutura funcional

- especialização tecnológica

- processos de trabalho e padrões de comportamentos

- dimensionamento de recursos humanos

Dentro desse estudo destaca-se a estrutura funcional e o dimensionamento de recursos humanos.

A estrutura organizacional cuida da divisão do trabalho com o arranjo e a inter-relação das funções necessárias à operação hoteleira, por meio do estabelecimento de órgãos e postos de trabalho. Fayol $^{1}$ (1975) considera seis funções essenciais nas empresas, segundo a Teoria Clássica da Administração:

- funções técnicas, voltadas à produção dos bens e serviços;

- funções comerciais, relacionadas à venda, compra e permutação;

- funções financeiras, envolvendo captação e gerência de capitais;

- funções contábeis, relacionadas a registros, balanços, custos, estatísticas;

- funções de segurança, envolvendo proteção e preservação de bens e pessoas;

\footnotetext{
${ }^{1}$ Fundador da Teoria Clássica da Administração e autor de Administração Industrial e Geral
} 
- funções administrativas, relacionadas à integração das outras funções, coordenando-as e pairando sempre acima delas.

As características de cada empreendimento dependerá da qualificação de recursos e a divisão do trabalho. Independentemente do tamanho, o hotel precisará distribuir o trabalho proporcionalmente à quantidade de funcionários, exigindo uma estruturação por parte do setor de recursos humanos. Contemplam-se as funções essenciais podendo ser agrupadas de formas diferentes, na organização da hotelaria tradicional. Os equipamentos necessários e instalações dão suporte às funções descritas abaixo visando enfatizar a estrutura da hotelaria tradicional.

Quadro 1 - Funções essenciais da empresa hoteleira

\begin{tabular}{|c|c|c|}
\hline FUNÇÕES TÉCNICAS & FUNÇÕES COMERCIAIS & FUNÇÕES ADMINISTRATIVAS \\
\hline Recepção & Vendas & Planejamento \\
\hline Governança & Marketing & Recursos humanos \\
\hline Reservas & Promoção & Compras \\
\hline Alimentos e bebidas & Relações públicas & Informática \\
\hline Telefonia & Propaganda & Transporte \\
\hline Eventos & Assessoria de imprensa & Almoxarifado \\
\hline Entretenimento & & Serviços gerais \\
\hline Lavanderia & & Controles operacionais \\
\hline Serviços diversos & & \\
\hline FUNÇÕES FINANCEIRAS & FUNÇÕES CONTÁBEIS & FUNÇÕES DE SEGURANÇA \\
\hline Contas a receber & Contabilidade & Manutenção predial \\
\hline Contas a pagar & Balanço patrimonial & Manutenção de equipamentos \\
\hline Tesouraria & Apropriação de custos & Vigilância \\
\hline Fluxo de caixa & Auditoria & Prevenção de incêndios \\
\hline
\end{tabular}




\begin{tabular}{|l|l|l|}
\hline Aplicações financeiras & Estatística & Preservação ambiental \\
\hline Captação de recursos & & \\
\hline Orçamentos & & \\
\hline
\end{tabular}

Fonte: Petrocci (2002:48)

Essas funções servem como órgãos de linha², envolvidos diretamente na prestação de serviços.

A estrutura organizacional na hotelaria define-se como tarefas, e são divididas, agrupadas e coordenadas. A estrutura organizacional é representada graficamente por retângulos e linhas verticais ou horizontais, o organograma organizacional.

Os órgãos de apoio destacam-se em negrito na estrutura básica do organograma de hotel de grande porte descrito abaixo:

Figura 2 - Estrutura de um hotel de grande porte

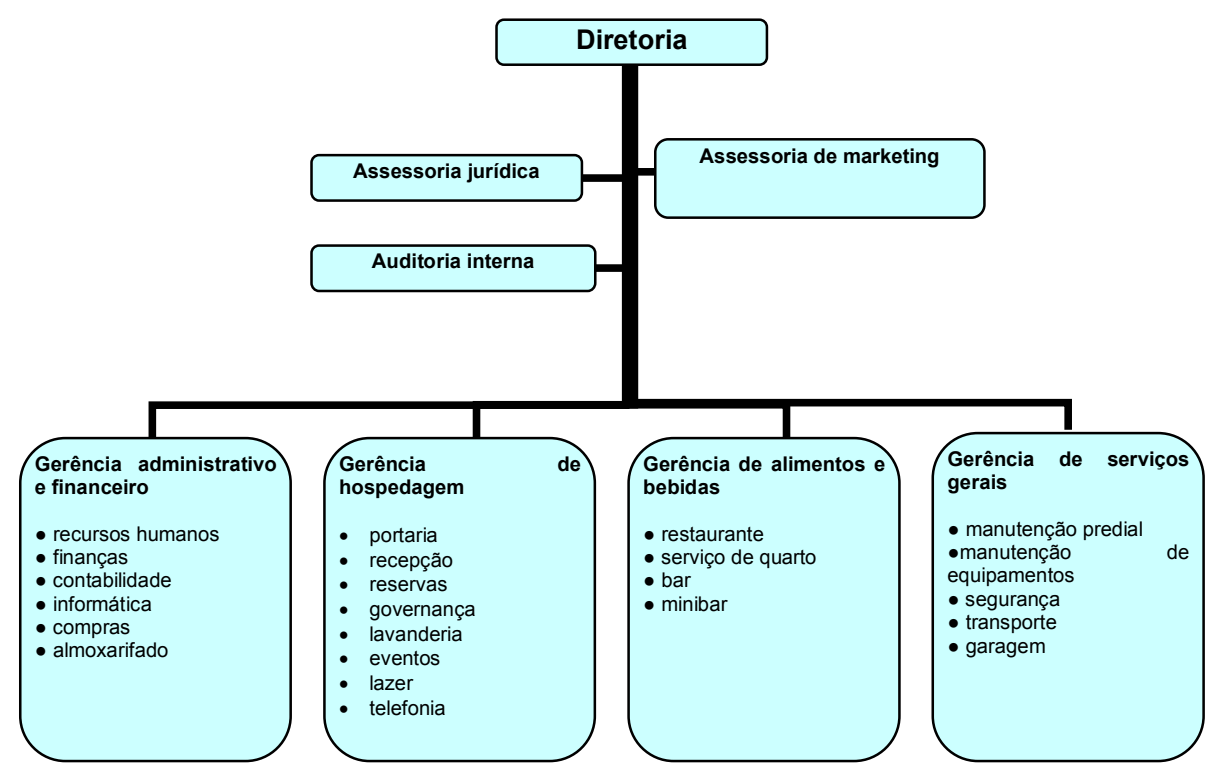

Fonte:Petrocchi (2002:54)

${ }^{2}$ É aquele que se envolve diretamente com a prestação dos serviços e é também conhecido como frontt office. 
O organograma mostra qual é a forma de organização dos setores e sua hierarquização, inter-relação e organiza o desencadeamento dos serviços a serem ofertados.

O hotel deve dispor de serviços com qualidade, cortesia, resposta rápida, preço justo, conveniência, entretenimento e ambiente acolhedor, buscando dessa forma ser competitivo no seu mercado, pois as mudanças afetam os valores e opiniões das pessoas, sugerindo também novas preferências, como a tecnologia, que mesmo apesar de trazer inovações e aperfeiçoamentos para a hotelaria, ainda dependem da opinião do cliente em todo processo de acolhimento.

Além de avanços tecnológicos e de gestão, o hotel deixou de possuir somente destinados a hospedar pessoas, para integrar-se ao seu entorno e oferecer espaços multifuncionais, voltando-se também, para eventos empresariais e acontecimentos sociais. Em todas as atividades, o hotel deve perseguir a satisfação dos clientes, em busca de sua sobrevivência. Petrocci (2002: 20).

$\mathrm{Na}$ análise operacional de uma empresa hoteleira, estabelece-se a existência de vários clientes: fornecedores e clientes internos e externos, onde se formam uma cadeia de processos.

Quadro 2 - Cadeia de processos

\begin{tabular}{|c|l|l|l|}
\hline Fornecedor & Cliente/Fornecedor & & Cliente \\
\hline Portaria & & & Governança \\
\hline
\end{tabular}

Fonte: Castelli (2001:85) 
São por meios desses fornecedores e clientes investigam-se uma seqüência de fluxos na busca de um melhor atendimento para entrada de serviços com qualidade, possibilitando percepção melhor a estruturar/fluxo das áreas e uma melhor compreensão do sistema de classificação dos meios de hospedagem.

\subsubsection{SISTEMA DE CLASSIFICAÇÃO DOS MEIOS DE HOSPEDAGEM}

O sistema de classificação dos meios de hospedagem tem a função de sistematizar os vários tipos e diferentes categorias dos meios de hospedagem e outras segmentações, e são úteis para o estudo dos empreendimentos hoteleiros.

Os sistemas de classificação identificam-se como Autoclassificação onde o estabelecimento se autoclassifica sem se comparar com os outros; classificação privada feita por organizações privadas que estabelecem os critérios procurando se enquadrar seguindo os mesmos para a classificação hoteleira; e a classificação oficial que é implantada por autoridades seguindo critérios e requisitos predeterminados. Castelli (2001: 60).

Segundo Longanese (2004:30), "O Sistema Oficial de Classificação dos Meios de Hospedagem é um instrumento para a promoção do desenvolvimento da indústria hoteleira, cabendo classificar, categorizar, qualificar os meios de hospedagem e, território nacional, simbolizado por estrelas, de acordo com as condições de conforto, comodidade, serviços e atendimento que possuam".

A Associação Brasileira da Indústria de Hotéis - $\mathrm{ABIH}$, em parceria com o EMBRATUR, está consolidando o novo processo de classificação de hotéis, através do Sistema de Classificação dos Meios de Hospedagem, o qual está vigorando oficialmente. O que as categorias prevêem são os variados tipos de empreendimentos, desde o super luxo ao econômico.

Hoje o mercado exibe novos conceitos, o que exige a modernização de um novo sistema de meios de classificação dos meios de hospedagem. De acordo com 
Castelli (2001), antigamente, por volta dos anos 70, na classificação atribuía-se $70 \%$ dos pontos para aspectos construtivos, os equipamentos e instalações, e somente $30 \%$ deles aos serviços. O que se vê hoje é exatamente o contrário. "O produto hoteleiro é um somatório de bens e serviços que devem primar pelo seu equilíbrio". Não se deve dizer que pelo fato de se ter um belo prédio com equipamentos e instalações excelentes tem-se um ótimo produto hoteleiro, enquanto que os serviços deixam a desejar, torna-se também inversamente verdadeiro, por isso a grande importância do equilíbrio para se ter o encantamento do cliente dependerá tão somente disso.

Segundo Longanese (2004:31), O sistema de classificação dos meios de hospedagem no Brasil deverá ser coordenado e supervisionado pelo Conselho Técnico Nacional, que terá poderes até mesmo para apreciar em grau de recursos e aprimorar a implantação e o funcionamento desse sistema, cabendo-lhe designar e substituir os membros dos Comitês de Classificação Regional. E através dos resultados dos da conclusão dos trabalhos pelo Conselho de Ética da União modificando o Regulamento Geral dos Meios de Hospedagem, o Manual de Avaliação e a Matriz de classificação, criados pela deliberação normativa $n^{\circ} 387$, de 28 de janeiro de 1998.

\subsubsection{MATRIZ DE CLASSIFICAÇÃO}

Desde abril de 2002, entrou em vigor com instrumentos da nova matriz de classificação que busca, entre outros incentivar os hotéis à fazerem o monitoramento dos gastos de energia e água, da produção e disposição dos resíduos, treinarem as equipes para tarefas como separação seletiva de lixo, limpeza dos ambientes com baixo gasto de água e acompanhamento do consumo de energia. 
A matriz de classificação tem como objetivo responder as expectativas dos hóspedes, aplicando-se ao meio de hospedagem quanto aos itens gerais com Posturas legais; Segurança; Saúde e higiene; Conservação e manutenção; Atendimento ao hóspede; e os itens específicos avaliando os diferentes setores dos meios de hospedagem como Portaria e recepção; Acessos e circulações; Setor habitacional; Áreas sociais; Comunicações; Alimentos e bebidas; Lazer; Reuniões e escritório virtual; Serviços adicionais; Ações ambientais (Langanese, 2004).

Seguindo a linha desses itens gerais e específicos, observa-se que os serviços prestados, a gestão adotada, as instalações, e aspectos construtivos, analisados juntos permitem verificar os níveis de qualidade no atendimento e conforto oferecidos ao hóspede.

$\mathrm{Na}$ hotelaria tradicional percebe-se que existe um grande elo entre os itens específicos descritos acima, esses servirão como base para implantação da hotelaria hospitalar, que surge para inovar os serviços prestados dentro de um hospital. 


\subsection{HOSPITAL}

O Hospital é definido como um local destinado ao atendimento de doentes, para tratamento de saúde ou algum trauma, proporcionando um diagnóstico e tratamento no qual necessite. Para Boeger (2005), à medida que a medicina foi desenvolvendo e de acordo com as peculiaridades de cada região, o hospital assumiu características específicas.

A missão do hospital é oferecer a excelência na qualidade nos serviços prestados, conquistando assim a satisfação do cliente de saúde. O termo hospital inclui desde o pequeno, aquele com estrutura informal, até as grandes organizações nos dias atuais, que visam atingir objetivos definidos e racionalizar os esforços humanos.

Antigamente, desde que o médico fosse um profissional competente e o hospital estivesse aparentemente limpo, nada mais importava para o paciente.

A estrutura organizacional nos hospitais é feita pela formação dos setores como um todo, cada qual com suas respectivas funções e responsabilidades.

Segundo Godoi (2004: 31), "Os hospitais possuem geralmente uma administração sisuda e conservadora que dificulta a melhoria sistemática em suas instalações".

De acordo com Godoi as divisões do organograma são de grande importância para a organização, pois se estiverem dentro da padronização, junto à rotina do hospital, recebem então o Certificado da Acreditação. 


\subsubsection{ACREDITAÇÃO}

Acreditação é um método de avaliação e estimulo da qualidade dos serviços de saúde onde são listados padrões de qualidade nas instituições hospitalares, sendo organizados por grau de satisfação podendo alcançar um nível de qualidade superior.

Segundo Godoi (2004: 96), há uma metodologia específica a ser utilizada para que haja a Certificação Hospitalar (Acreditação). O Manual Brasileiro de Acreditação Hospitalar (2001) tem sido o instrumento utilizado para avaliação da qualidade das instituições hospitalares, composto de seções e subseções. Nas subseções existem os padrões definidos segundo três níveis, do mais simples ao mais complexo, do inicial ao mais desenvolvido, e sempre com um processo de incorporação de requisitos anteriores de menor complexidade. Para cada nível são definidos itens de verificação que orientam a visita e preparação do hospital, para a Acreditação Hospitalar. Através da mesma, a instituição de saúde tem a capacidade de fazer um diagnóstico do desempenho dos processos, sejam elas as atividades de cuidado direto ao paciente e aquelas de natureza administrativa. A partir desse diagnóstico, de acordo com o Manual de padrões de Acreditação Hospitalar, é possível discutir o que se foi encontrado na avaliação para assim desenvolver um plano de ações promovendo a melhoria do desempenho da instituição, atingindo todos os segmentos e serviços existentes.

Quando uma instituição de saúde recebe a Certificação Hospitalar, significa que nela existem padrões de qualidade a que ela se propôs voluntariamente. A Certificação não garante por si só essa qualidade, trata-se ma verdade de um processo contínuo de produção e melhoria do atendimento médico hospitalar. Godói (2004: 94) 
Para adquirir a Acreditação, o responsável pela Instituição de Saúde deve solicitar uma avaliação, devendo essa ser feita sob medida, baseando-se pelas características do hospital. Ocorre então a primeira avaliação: quando se verifica a conformidade da estrutura, dos processos e dos resultados obtidos pelo hospital, comparados com padrões pré-estabelecidos. Os avaliadores fornecem ao hospital um relatório de decisão preliminar, baseado em seus achados durante a avaliação, e esse é enviado ao Comitê de Acreditação, que tem entre suas atribuições a aprovação do relatório e a outorga da acreditação. A duração do ciclo de acreditação é de três anos, seis meses antes da data de seu término, a agência acreditadora notifica a instituição, com vistas à realização de nova avaliação para reacreditação e um novo ciclo tem início.

Retomando uma discussão dos Meios de hospedagem, cabe reforçar que os hotéis utilizam o sistema de classificação e de categorização para se enquadrar, oferecendo conforto, comodidade e serviços. Já os hospitais se utilizam do sistema de acreditação para adquirir os padrões de qualidade exigidos pela mesma. Faz-se necessário a construção de novos modelos adaptados a hotelaria hospitalar buscando o desenho dos elementos que possam ser aproveitados de ambos os processos. 


\section{HOTELARIA HOSPITALAR}

A hotelaria hospitalar nasceu no Brasil há pouco menos de uma década e está sendo cada dia mais utilizada pelos hospitais em todas as regiões. Foi criada em virtude de diversos fatores, sendo o principal o paciente, que começou a questionar sobre suas necessidades, exigindo que a empresa lhes ofereça não só o tratamento, bem como a segurança, o conforto, e o bem estar da sua família e seus visitantes.

Nos dias atuais a hotelaria hospitalar vê o hospital como um hotel de clientes com várias necessidades e um grau maior de sensibilidade. Logo, reunir serviços oferecidos em hotéis a esse público tornará sua convalescença menos traumatizante e menos desgastante para os pacientes. Godoi, (2004: 41, 42),

A hotelaria hospitalar vem surgindo como tendência para transformar ambientes e processos operacionais agregando mais qualidade para a instituição, nos mesmos moldes das hotelaria tradicional. A maior preocupação é oferecer um serviço diferencial para atender ao cliente de saúde desde a recepção, o serviço de quarto à sua alta.

Godoi (2004: 40), define hotelaria hospitalar como "a introdução de técnicas, procedimentos e serviços de hotelaria em hospitais como o conseqüente benefício social, físico, psicológico e emocional para os pacientes, familiares e funcionários".

Já na concepção de Boerge (2005: 24), "a Hotelaria Hospitalar é a reunião de todos os serviços de apoio, que associados aos serviços específicos, oferecem aos clientes internos e externos, conforto e bem-estar durante o seu período de internação".

Uma das ferramentas para alcançar estes objetivos é a departamentalização, cujas vantagens são as facilidades para identificar cada setor, determinar as 
responsabilidades, permitir criar e inovar, a partir da integração e a comunicação entre os setores, obtendo então a qualidade nos serviços prestados.

Os serviços de hotelaria que devemos implantar e adaptar no ambiente hospitalar precisam ser identificados; para isso; há a necessidade de lhes dar identidade própria para que possam ser distinguidos dos demais serviços hospitalares, ocupando seu espaço no organograma geral e, conseqüentemente, serem percebidos pelos clientes de saúde. Nada melhor que departamentalização para tornar esses serviços visíveis, agrupando-os em unidades organizacionais, de acordo com um critério específico de homogeneidade. (Tarabousi, 2006: 57).

A Hotelaria hospitalar propõe implantar, inovações nas diversas áreas de um hospital. Seu responsável deverá ter visão administrativa e capacidade para gerir a interação dos setores existentes. A partir do planejamento, organização e supervisão, estabelecendo ambiente de harmonia e confiança entre os diversos setores como direção, corpo clínico e outros; treinamento das equipes, inserindo avaliações de desempenho para cada setor ou departamento da hotelaria; acompanhamento do processo seletivo para profissionais da hotelaria junto ao departamento de Recursos Humanos, procurando uma melhor adaptação do serviço hoteleiro ao hospitalar.

A qualidade deve ser um fator determinante e constante na hotelaria hospitalar gerando resultados positivos a cada dia, crescendo com o grau de satisfação interna dos médicos e funcionários, bem como paciente, acompanhantes e sociedade numa escala multiplicadora

A grande influência na estrutura também se dá pelos cargos de chefia e supervisão, executando a automatização dos trabalhos, mudando e organizando as rotinas, racionalizando o tempo das operações e as atividades executadas. Destaca-se em negrito os setores que compõe as funções essenciais de uma empresa hoteleira, portanto, podendo ser adaptada as instituições hospitalar. 
Quadro 3 - Funções essenciais da empresa hoteleira

\begin{tabular}{|c|c|c|}
\hline FUNÇÕES TÉCNICAS & FUNÇÕES COMERCIAIS & FUNÇÕES ADMINISTRATIVAS \\
\hline Recepção & Vendas & Planejamento \\
\hline Governança & Marketing & Recursos humanos \\
\hline Reservas & Promoção & Compras \\
\hline Alimentos e bebidas & Relações públicas & Informática \\
\hline Telefonia & Propaganda & Transporte \\
\hline Eventos & Assessoria de imprensa & Almoxarifado \\
\hline Entretenimento & & Serviços gerais \\
\hline Lavanderia & & Controles operacionais \\
\hline \multicolumn{3}{|l|}{ Serviços diversos } \\
\hline FUNÇÕES FINANCEIRAS & FUNÇÕES CONTÁBEIS & FUNÇÕES DE SEGURANÇA \\
\hline Contas a receber & Contabilidade & Manutenção predial \\
\hline Contas a pagar & Balanço patrimonial & Manutenção de equipamentos \\
\hline Tesouraria & Apropriação de custos & Vigilância \\
\hline Fluxo de caixa & Auditoria & Prevenção de incêndios \\
\hline Aplicações financeiras & Estatística & Preservação ambiental \\
\hline \multicolumn{3}{|l|}{ Captação de recursos } \\
\hline Orçamentos & & \\
\hline
\end{tabular}

Fonte: Petrocci (2002:48)

Atualmente o que se é vivenciado nos hospitais são as mudanças na arquitetura com seus profissionais, a programação social, a inclusão dos serviços de hotelaria como capitão-porteiro, mensageiros e assistentes de hotelaria uniformizados e capacitados para receber o cliente de saúde, como também o turismo, gastronomia, decoração e paisagismo entre outras áreas, exaltando a semelhança entre um hospital e um hotel. Quem entra em um saguão de hospital que aplique a hotelaria hospitalar 
tem a sensação de estar num ambiente de hotel de primeira linha. Cheiro de éter, ambiente frio, os clientes tumultuados à espera de atendimento são coisas do passado.

A estrutura organizacional da hotelaria hospitalar varia de amplitude de um hospital para outro, principalmente porque ainda não é um serviço completamente sedimentado e, como tal, não faz parte do cenário rotineiro de todo hospital.

Figura 3 - Organograma básico do departamento de hotelaria

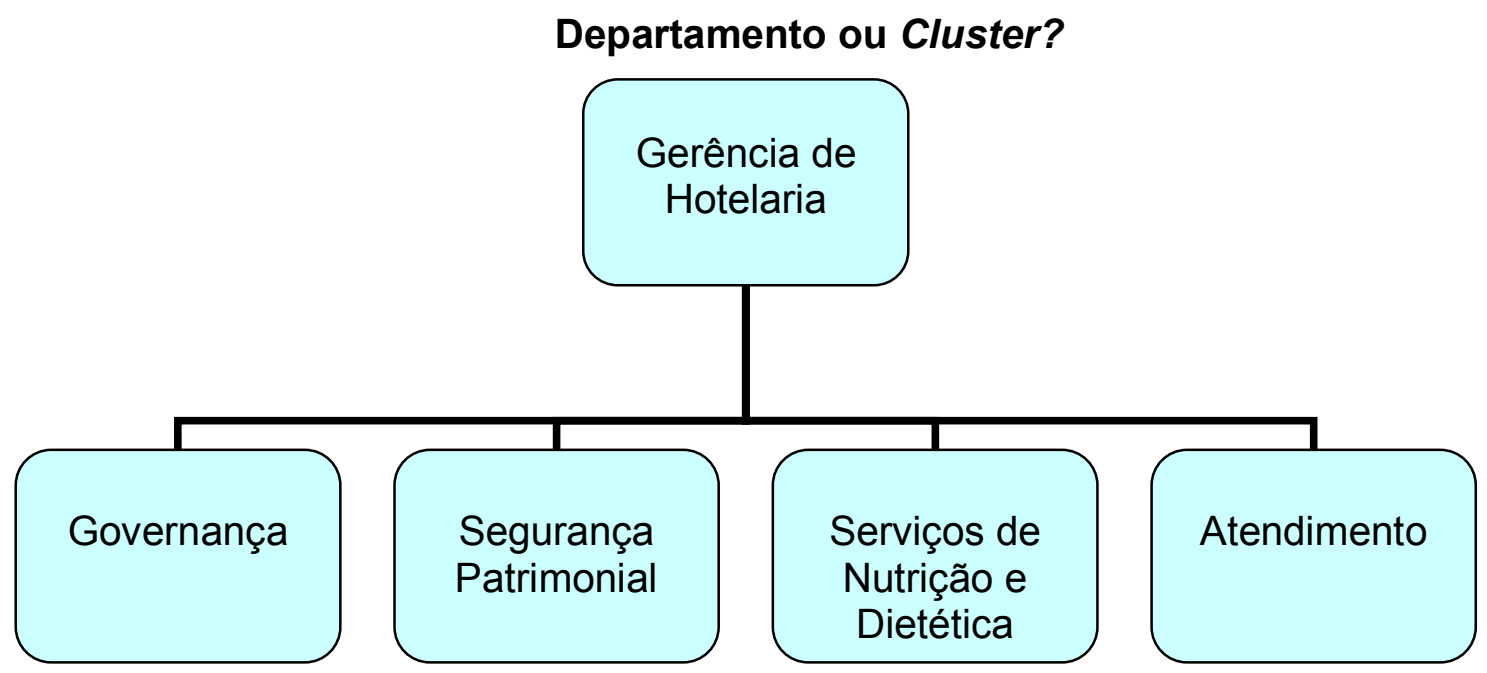

Fonte: Boeger (2005: 26)

Já para Tarabousi (2006: 58) a hotelaria hospitalar é o departamento principal, responsável pela implantação, organização, coordenação e controle de todos os serviços de hotelaria a serem inseridos. 
Figura 4 - Organograma administrativo do hospital

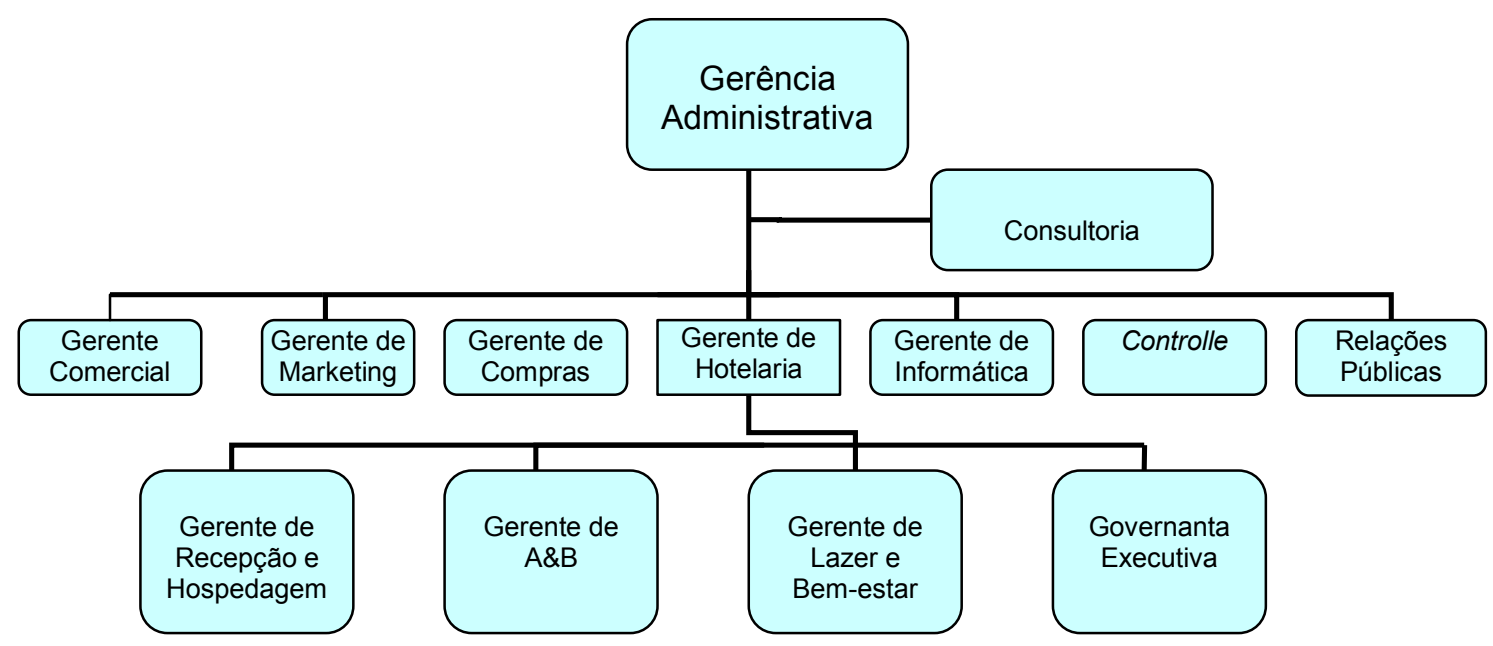

Taraboulsi (2006:59)

A partir dos organogramas apresentados dos autores Boeger e Taraboulsi pode-se perceber que ambos destacam uma Gerência de Hotelaria específica, e áreas de governança; de $A \& B$, de Recepção como imprescindíveis no funcionamento da Hotelaria hospitalar, em destaque para a área de segurança e patrimonial, que na estrutura apresentada por Taraboulsi está diluída em todas as áreas. 


\subsection{Matriz de classificação hotelaria hospitalar ${ }^{3}$}

A matriz de hotelaria é um instrumento composto de requisitos para classificação de padrões de serviços e produtos do empreendimento. A matriz apresentada é estruturada de 17 grupos distribuídos em 142 itens adaptados para a hotelaria hospitalar, como seguem: Posturas legais; Segurança; Saúde higiene; Conservação e Manutenção; Atendimento ao hóspede; Portaria e recepção; Acessos e circulações; Setor habitacional; Áreas sociais; Comunicações; Alimentos e bebidas; lazer; Eventos; Serviços adicionais; Ações ambientais; Médico; Informática e comercial. Para Longanese (2004: 39), "esses padrões verificarão, em cada item, os serviços prestados pelo estabelecimento, os sistemas de gestão adotados, as instalações e os equipamentos disponíveis, bem como as áreas e os aspectos construtivos existentes no meio de hospedagem que, analisados em conjunto, possibilitarão aferir os níveis de conforto e atendimento oferecidos aos consumidores". Através dessa análise pode-se constatar se esses padrões recebem ou não um suporte dos serviços compatíveis.

\footnotetext{
${ }^{3}$ A matriz de classificação da hotelaria hospitalar é um documento produzido pelo CET - Centro de Excelência em Turismo - UnB - 2008, foi adaptada com base na matriz hoteleira oficial que contém 18 grupos contendo 142 itens ao todo.
} 


\subsection{Serviços Compatíveis}

$\mathrm{Na}$ área hospitalar existem vários serviços que dão apoio com suas atividades meio e fim: as equipes de Recepção e internação; Emergência, Enfermagem; Nutrição e dietética; Segurança patrimonial e Manutenção. O que se vê nas instituições que mais deixa a desejar são aspectos como organização, atendimento adequado, cortesia e respeito, e segundo Tarabousi (2006: 51) "Hotelaria é a arte de oferecer serviços repletos de presteza, alegria, dedicação e respeito, fatores que geram a satisfação, o encantamento do cliente". Um fator importante de ressaltar é a capacidade de gerenciar, cada gestor tem a responsabilidade de identificar e filtrar os serviços que devem ser implantados e adaptados no ambiente hospitalar.

O segmento da hotelaria hospitalar poderá orientar-se de maneira adequada para a execução das atividades feitas pelos seus colaboradores, organizando-se de forma adequada alcançando a maior produtividade possível considerando as demandas, a extensão dos recursos necessários, de acordo com cada setor, levandose em conta o volume das atividades e o perfil das pessoas da instituição. De acordo com Caon (2008: 84), "A satisfação do funcionário auxilia na retenção e produtividade do mesmo. Na maioria dos serviços o custo real de um alto índice de rotatividade da mão-de-obra é constituído pela perda da produtividade e pela diminuição da satisfação do cliente".

A hotelaria hospitalar é uma proposta que busca um novo perfil do profissional de saúde. Portanto, não há mão-de-obra especializada para atuar nos serviços de hotelaria a serem introduzidos no ambiente hospitalar. É mister o investimento em treinamento para adequada adaptação à atividade hospitalar quando da contratação de profissionais de hotelaria. Taraboulsi (2006: 56). 
O que observamos é que nenhum serviço pode oferecer vantagens em relação a outros similares se não for capaz de formar um todo entre sua finalidade, as etapas de produção e seus benefícios. A existência da padronização vem para dar todo o suporte e definição para as rotinas a serem executadas. 


\section{PADRONIZAÇÃO}

Segundo o dicionário Aurélio (2009) o termo Padronização, significa, “ Ação ou efeito de padronizar; sistematização. / Processo de formação de padrões sociais; estandardização. / Indústria Uniformização dos tipos de fabricação em série, pela adoção de um único modelo".

A padronização nos serviços prestados na hotelaria hospitalar serve como apoio para oferecer a qualidade e diferencial no atendimento, segundo Lamprecht (1997: 86). Depois de definidos todos os processos ou atividades, algumas regras básicas devem ser obedecidas, antes de qualquer processo ser padronizado. Recomenda-se que antes de escrever as rotinas, ou treinar as pessoas, cada processo seja avaliado, como o objetivo de verificar se estes estão atendendo aos padrões preestabelecidos, ou se podem ser melhorados.

\footnotetext{
O trabalho que as pessoas executam pode ser feito de inúmeras maneiras. É o caso, por exemplo, da arrumação de um apartamento, feito pelas camareiras. Dentre os vários procedimentos existem alguns que certamente são melhores do que outros. É preciso descobrir qual é o melhor deles e, em seguida, adotá-lo. Este passa a ser o Procedimento Operacional Padrão - POP, que deve ser registrado e seguido por todas as pessoas envolvidas com a tarefa em questão até se descobrir uma outra maneira ainda melhor de fazê-los. Castelli (2001: 97)
}

Para melhor entendimento, um exemplo importante a ser citado, na parte de limpeza, é a existência do Manual de Procedimento Padrão. É um documento passado para os funcionários que poderão através dele seguir uma rotina com a padronização de como se devem desenvolver as atividades relacionadas à limpeza, ao mesmo tempo a chefia pode ter o controle e fiscalizar o serviço de higiene. Esse manual é elaborado e redigido, de forma reduzida, pela chefia do serviço de higienização junto com o $\mathrm{CCIH} \mathrm{-}$ Comissão de Controle de Infecção Hospitalar, considerando fundamentos de técnicas e 
práticas com os passos mais críticos de forma simples para um fácil entendimento dos colaboradores que irão executar.

Segundo a ANVISA (2009), "O Procedimento Operacional Padrão (POP), seja técnico ou gerencial, é a base para garantia da padronização de suas tarefas e assim garantirem a seus usuários um serviço ou produto livre de variações indesejáveis na sua qualidade final".

Para que essa padronização seja realizada de maneira eficaz a Gestão de cada setor deve preocupar-se em realizar treinamento, fornecendo manuais a serem seguidos pelas equipes, dando então suporte para os indicadores de desempenho. 


\section{INDICADORES}

Os indicadores de desempenho servem como objetivos e processo de planejamento através de especificações, selecionada o que melhor indique, evolui em direção aos objetivos estratégicos estabelecidos.

De acordo com Petrocchi (2002: 148) "Os indicadores devem aferir o desempenho de cada setor. Eles observam uma determinada hierarquização e se distribuem na estrutura hoteleira, estabelecendo metas para os diversos setores especializados da organização." Como exemplo, a direção será responsável pelos objetivos estratégicos gerais da instituição, os responsáveis de cada setor responderão pelos desempenhos indicados para cada um deles, e em toda a organização o andamento será refletido através do conjunto desses indicadores de desempenho.

As reclamações e aprovações dos hóspedes são indicadores essenciais para orientar a administração hoteleira, pois é através dessas reclamações que se sabe se está agradando ou não o cliente, podendo então corrigir os problemas e aumentar as vantagens competitivas. Petrocchi (2002) descreve as áreas de possíveis indicadores de desempenho: Direção; Recepção; Telefonia; Reservas; Eventos e lazer; Governança, Alimentos e bebidas; Vendas; Promoção; Internet; Recursos humanos; Área financeira; Serviços gerais; Informática e Manutenção.

Destaquemos o setor de governança, objeto do estudo:

- Nível de satisfação dos hóspedes; Número de reclamações de hóspedes; Anomalias nas UH s indicadas pelos hóspedes; Erros na elaboração dos relatórios de ocupação das UHs; Erros na indicação de consumo no minibar; Anomalias na rouparia; Anomalias da lavanderia; Anomalias na limpeza e arrumação das áreas sociais. 
Em todas as etapas dos indicadores de desempenho, existe a fase de gerenciar que busca atingir metas, destacando que toda ela é mensurável, digo, não se pode gerenciar o que não se pode medir, avaliar o desempenho parcial da empresa, buscando melhorias contínuas, permitindo, através dos indicadores acompanharem os bens, serviços e respectivos processos. Castelli (2001).

Quadro 4 - Os indicadores da qualidade em serviços destacam:

\begin{tabular}{|c|c|c|c|c|}
\hline Serviço & $\begin{array}{c}\text { Dimensões da } \\
\text { Qualidade }\end{array}$ & Indicadores & Medidas & Padrões \\
\hline \multirow[t]{3}{*}{ Restaurante } & \multirow[t]{2}{*}{ Rapidez } & \multirow{2}{*}{$\begin{array}{l}\text { Pouca demora } \\
\text { após o pedido }\end{array}$} & Tempo de pedido & \multirow{2}{*}{$\begin{array}{l}\text { De } 15 \text { a } 20 \\
\text { minutos }\end{array}$} \\
\hline & & & Tempo de entrega & \\
\hline & $\begin{array}{l}\text { Cortesia/ } \\
\text { amabilidade }\end{array}$ & Sorrir, agradar & $\begin{array}{l}\text { Pesquisa com } \\
\text { escala: muito } \\
\text { satisfeito; satisfeito; } \\
\text { regular } \\
\text { insatisfeito }\end{array}$ & $\begin{array}{l}90 \% \text { muito } \\
\text { satisfeito; } \\
0 \% \text { abaixo } \\
\text { de regular }\end{array}$ \\
\hline
\end{tabular}

Fonte: Castelli (2003: 88)

A base dos indicadores utilizados foi de restaurantes só para se ter elementos de referência que pudessem dar subsídios para trabalhar a área de governança. Já na mesma os indicadores prioritários é a boa qualidade na lavagem da roupa, a eficiência na limpeza das unidades habitacionais, uma central telefônica responsável em receber todas as solicitações e providenciar a distribuição das mesmas aos seus setores. 
Através desses indicadores da qualidade em serviços é possível identificar e alinhar de forma que possa destacar os pontos positivos e negativos para estar oferecendo os melhores serviços com qualidade . 


\title{
5 QUALIDADE
}

A busca incessante pela qualidade tem se tornado um dos grandes objetivos dos hospitais, principalmente em função da cobrança do seu principal cliente que é o paciente.

\begin{abstract}
"Nota-se que cada vez mais os conceitos de qualidade vêm sendo aprimorados e o atendimento ao cliente vem sofrendo transformações. A perfeição esperada pelos clientes quanto aos procedimentos médicos já é, neste século, graças à tecnologia, uma obrigação das instituições de saúde. Embora isso seja entendido pela grande maioria dos hospitais, muitos deles ainda não possuem gestão direcionada para esse mercado. (Boeger, 2005: 24).

"No sentido mais amplo, Qualidade é qualquer coisa que pode ser melhorada. Nesse contexto, a Qualidade é associada não apenas aos produtos e serviços, mas também à maneira como as pessoas trabalham, como as máquinas são operadas e como o sistema e procedimentos são elaborados. Ela inclui todos os aspectos do ser humano". (Castelli, 2002: 19).
\end{abstract}

A qualidade nos serviços está adequando-se às necessidades do cliente, preocupando-se em prestar um atendimento personalizado a fim de que esse paciente sinta-se bem em estar naquele ambiente totalmente desconhecido e estranho para ele. Para que isso aconteça de forma eficaz a instituição de saúde deve preocupar-se em treinar seus colaboradores de forma que os mesmos prestem serviço com qualidade, para que dessa forma exista um diferencial no atendimento prestado. Segundo Castelli (2001: 77) "Satisfazer significa atender as necessidades das pessoas, através de bens e serviços com qualidade". Qualidade em todas aquelas dimensões que afetam a satisfação das pessoas, ou seja:

* Qualidade intrínseca: São as características próprias dos bens e serviços, finais ou intermediários, como: durabilidade, originalidade, aparência agradável. Os bens e serviços são revestidos de características como horários, conforto, limpeza, entrega, custo, moral e segurança. 
Para que exista a qualidade no atendimento ao paciente o hospital depende de um fator importante que é a humanização ${ }^{4}$ no serviço prestado, pois para atender pessoas com problemas de saúde necessita-se de uma maneira especial de comunicação, e para isso exige-se treinamento do pessoal que presta esse serviço. Pode parecer evidente que o atendimento no hospital deva ser indispensavelmente humano, mas na realidade isso ainda não é uma verdade para todas as instituições.

Se houver maiores investimentos, se a qualidade do atendimento melhorou e há maior qualificação na área da saúde, a hospitalidade praticada nos hospitais teoricamente deveria acompanhar essa tecnologia e não diferir de uma instituição de saúde para outras de forma gritante. Godoi (2004: 40)

Antes a qualidade era considerada uma responsabilidade funcional, nos dias atuais, na visão da "Gerência da qualidade" ela transforma-se numa tarefa de todos com objetivo organizacional.

Para adquirir a excelência na qualidade um dos instrumentos usados é a aplicação da ISO $9000^{5}$. Lamprecht (1997: 29) enfatiza a série ISO 9000 - 9004 a sua existência a partir de 1987 quando os cincos ISO foram publicados pela Organização Internacional para a normalização, em Genebra, descritos abaixo:

ISO 9000-1 - Gestão da Qualidade e Normas para a Garantia da Qualidade: Diretrizes para Seleção e Uso;

\footnotetext{
4 Segundo Gheller (2005): "humanização é a palavra utilizada para falar da melhoria da qualidade do atendimento aos clientes. É o atendimento prestado com respeito, dignidade, ternura e empatia ao cliente e seus familiares".

5 A aplicação de um sistema de qualidade normalizado, como modelo descrito pela série ISO 9000, pode ajudar a corrigir essas deficiências e certamente ajudará a aumentar a satisfação do cliente. (Lamprecht, 1997: 28).
} 
ISO $9001^{6}$ - Sistemas da Qualidade - Modelo para a Garantia da Qualidade em Projeto, Desenvolvimento, Produção, Instalação e Serviços.

ISO 9002 - Sistemas da Qualidade - Modelo para a Garantia da Qualidade na Produção, Instalação e Serviços.

ISO $9003^{7}$ - Sistemas da Qualidade - Modelo para a Garantia da Qualidade na Inspeção Final e Testes.

ISO $9004^{8}$ - Elementos da Gestão da Qualidade e do Sistema da Qualidade Diretrizes.

ISO $14001^{9}$ - É a norma opcional, Ao contrário do que se pensa, não há exigências internacional oficial para empresas alcançarem a certificação ISO 14001.

Os documentos citados acima seguem diretrizes e devem ser usados como referência, ainda segundo Lamprecht, é de sua importância à aplicação e existência do Sistema das normas ISO em vários setores para então darem suporte e oferecerem a qualidade na prestação de serviços.

\footnotetext{
${ }^{6}$ A única diferença entra a 9001 e 9002 é o controle de projetos que está contido da Lista de Elementos do Sistema de Qualidade, que não se aplica à norma 9002.

7 Uma vez que a 9003 não é para ser usada na indústria da hospitalidade e por ser provável que a norma 9003 seja extinta quando ocorrer a próxima revisão da ISO 9000.

8 As Diretrizes da ISO 9004 devem ser usadas apenas como referência e não são normas de cumprimento obrigatório, ou seja, não podem ser usadas por auditores que realizem auditoria em sua própria organização.

9 A norma 14001 engloba vários temas, os mais importantes de planejamento, implementação e operação, verificação e ação corretiva e auditoria do sistema de gestão ambiental seguem o já conhecido modelo da garantia da qualidade.
} 


\subsection{Qualidade na prestação de serviço}

Organizações precisam funcionar como equipes que derrubam barreiras, em vez de criá-las. É importante qualificar as pessoas que integram a empresa, para atuarem de forma ótima em todos os momentos, é um episódio no qual o cliente entra em contato com qualquer aspecto da organização e obtém uma impressão da qualidade do seu serviço, pois o sucesso da empresa depende da mesma nesses momentos. Daí a importância de se elevar ao máximo o nível de desempenho de cada empregado, que, além de repercutir positivamente nos negócios da empresa elevará também, uma das necessidades fundamentais de todo o ser humano, a sua autoestima. Pessoas com qualidade pessoal elevada são um importante ativo para a empresa, pois a excelência de bens e serviços depende da qualidade dos processos, e estes da qualidade das pessoas que executam.

De acordo com Godoi (2004: 85), Qualidade nos serviços de saúde envolve uma correta adequação de todos os serviços prestados às necessidades que o paciente apresenta, superando as suas expectativas. Envolve basicamente a satisfação das necessidades do paciente, sendo algo intangível de difícil percepção por outrem. Como o paciente não é um produto, a qualidade assume novas dimensões e perspectivas, associadas com o tratamento.

Os serviços prestados com qualidade estão nas pessoas, pois elas ocupam lugar de destaque e fazem à diferença. Os equipamentos, as instalações e a tecnologia ficam em segundo plano. 


\section{DESCRIÇÃO DO ESTUDO}

\subsection{HOSPITAL SANTA LÚCIA}

Figura 5. Fachada do Hospital Santa Lúcia.

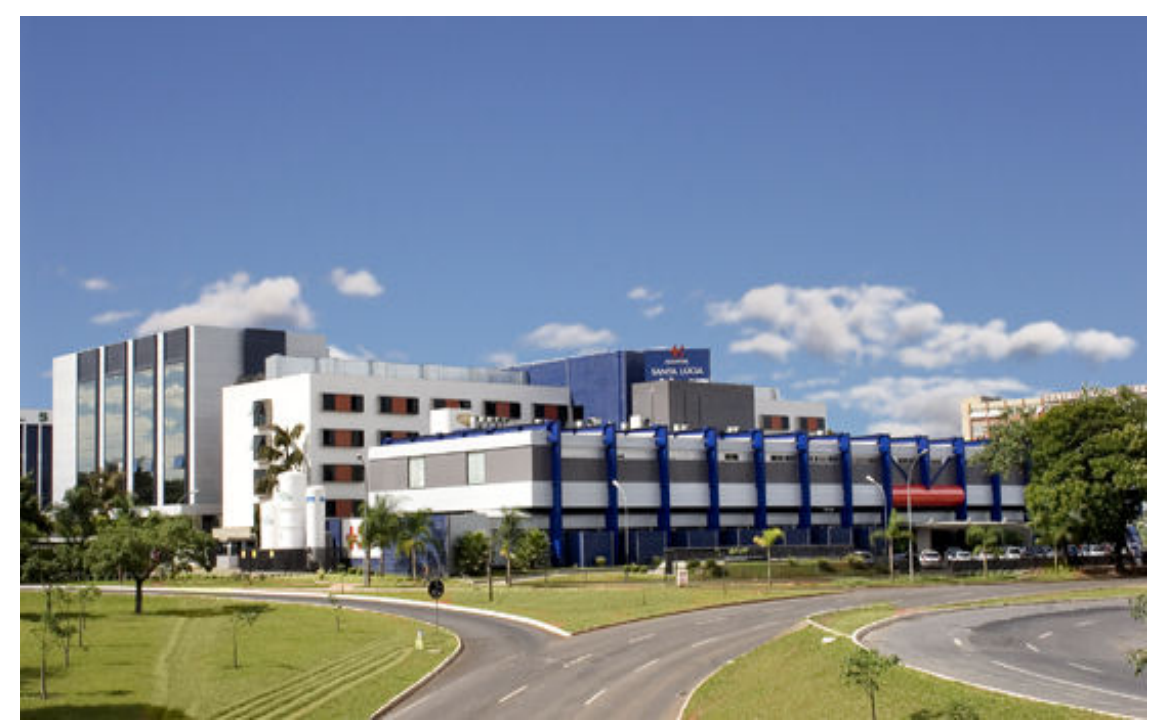

Fonte:www.marliere.com.br/santalucia/pages

Em 1963, acreditando no novo potencial da recém-inaugurada capital do país, um grupo de jovens médicos com espírito inovador, uniram-se para planejar o primeiro hospital da rede privada de Brasília. Uma iniciativa pioneira de profissionais que acreditaram no futuro da capital da República e trouxeram para Brasília a força de sua esperança e a certeza de sua determinação. Em 25 de novembro, foi lançada a pedra fundamental para a construção da Casa de Saúde Santa Lúcia: estava realizado o sonho dos jovens médicos, que cresceram com Brasília e acreditaram no seu potencial.

O caminho estava aberto. Em três anos o sonho tomaria formas concretas: na presença do então presidente da República, marechal Castelo Branco, e do governador do Distrito Federal, Plínio Catanhede, o projeto do arquiteto Nilton Ramos foi inaugurado em 8 de dezembro de 1966. Naquela década, o primeiro hospital particular 
do Distrito Federal precisou rever seu projeto inicial devido ao rápido crescimento de Brasília e à nova demanda de atendimentos.

O Hospital Santa Lúcia ocupa hoje uma área especial do Setor Hospitalar Sul na região central do Plano Piloto, coração do Distrito Federal. São mais de quatro décadas vislumbrando e alcançando o novo, trazendo para o coração do Brasil o melhor em saúde.

É hoje o mais bem equipado hospital privado do Centro-Oeste e conta com referência médica e tecnologia de ponta que o qualificam para atender às necessidades mais complexas.

Possui clínicas dedicadas às mais diversas especialidades médicas, com 250 leitos e os melhores equipamentos, voltados para o atendimento ao público. O pronto socorro e a unidade de atendimento médico cirúrgico atende a todas as especialidades médicas.

Futuramente contará com nova ala de construção que faz parte do projeto que contemplará uma área total construída de $30.000 \mathrm{~m}^{2}, 380$ vagas para veículos, área para praça de alimentação, comercial, auditório com 229 lugares, jardins de inverno, suspensos e heliporto.

Hoje o Hospital Santa Lúcia tem em sua direção os médicos, Dr. José do Patrocínio Leal, Dr. Hamilton Heitor de Queiroz e Dr. José Cardoso Machado. Cada diretoria tem sob sua subordinação os diversos setores que compõe a estrutura organizacional, esses setores são administrados por coordenadores que contam com encarregados para auxiliar a administração.

Os leitos do hospital Santa Lúcia estão distribuídos da seguinte forma:

$11^{\circ}$ andar: com 43 leitos individuais e 2 enfermarias com 2 leitos cada; 
$22^{\circ}$ andar: 30 leitos individuais e 2 enfermarias com 2 leitos cada;

$33^{\circ}$ andar: 40 leitos individuais e 1 enfermaria com 2 leitos cada;

$43^{\circ}$ andar maternidade: 19 leitos individuais;

$5 \quad 4^{\circ}$ andar: 36 leitos individuais e 2 enfermarias com 2 leitos cada;

6 Unidade de Tratamento Intensivo - UTI A: 27 leitos individuais;

7 Unidade de Tratamento Intensivo - UTI B: 10 leitos individuais;

8 Unidade de Tratamento Intensivo - UTI C: 24 leitos individuais;

9 Unidade de Tratamento Intensivo Neonatal - UTIN: 13 leitos individuais;

10 Unidade de Tratamento Intensivo Pediátrico - UTIP: 5 leitos individuais;

11 Unidade de Tratamento Medula Óssea - UTMO: 5 leitos individuais;

12 Posto pediátrico: 5 leitos individuais;

13 Radioterapia: 10 leitos individuais;

14 Quimioterapia: 40 leitos individuais;

15 SOS: 10 leitos individuais;

No quadro de pessoal os colaboradores efetivados de acordo com as necessidades de cada setor e a pedido do coordenador, tais procedimentos são feitos pelo departamento de recursos humanos que se responsabiliza também pelo treinamento dos selecionados.

Passam diariamente pelo pronto socorro do Hospital Santa Lúcia um total de 400 atendimentos emergenciais, totalizando 12 mil atendimentos por mês. Para internação é de aproximadamente 25 pessoas por dia, distribuídos em 4 andares e UTIs.

Pode-se notar que o hospital possui um fluxo demandante grande o que necessita de tal infra-estrutura existente no local. 
Os equipamentos do Hospital Santa Lúcia reúnem tecnologia médica, para diagnóstico e tratamento de problemas relacionados às mais diferentes áreas da ciência médica: Ressonância Magnética, Tomografia Computadorizada Helicoidal, Acelerador Linear, Braquiterapia de Alta Taxa, Litotripsia, Densitometria Óssea, Mamografia com aplicação de estereotaxia, Cineangeocoronariografia, Radiologia Geral, Ecografia de alta resolução, Ecocardiografia, Medicina Nuclear, Videolaparoscopia, Colonoscopia, Endoscopia Digestiva.

Rapidez e agilidade no tratamento de informações de interesse do Hospital e de seus pacientes. Esse é o objetivo da Central de Processamento de Dados do Hospital Santa Lúcia, que oferece os seguintes serviços:

- Controle automatizado desde a recepção até a alta do paciente

- Controle automatizado de despesas realizadas em cada setor do Hospital

- Controle de estoque

- Contabilidade

- Controle de pessoal

Os equipamentos existentes são os seguintes:

- 50 terminais interligados

- redes integradas:

Emergência

Radiologia

Internações

O Hospital Santa Lúcia oferece infra-estrutura para garantir o melhor 
atendimento ao paciente e à sua família.

- 25 clínicas

- Dezenas de apartamentos em 4 andares para internação

- 250 leitos

No Hospital Santa Lúcia o sistema completo é composto por:

- Administração

- Recepção informatizada

- Laboratórios

- Centro de Estudos

- Refeitórios

- Avançado Sistema Nutricional

Além de:

- Dois tanques criogênicos. Um para armazenar o Oxigênio líquido (a-183 $\left.{ }^{\circ} \mathrm{C}\right) \mathrm{e}$ outro para o Nitrogênio líquido $\left(\mathrm{a}-196^{\circ} \mathrm{C}\right)$.

- Misturador de Ar Medicinal Estéril, equipado com dois analisadores de O2, que garantem a máxima segurança da composição da mistura.

- Central Reserva de Ar Comprimido

- Grupo gerador de energia elétrica

- Central de filtragem de água hospitalar 
A equipe multiprofissional que cuida dos clientes pacientes é constituída por médicos, equipe de enfermagem, nutricionistas, psicólogos, assistentes de hotelaria, camareiras e auxiliar de higiene.

No Hospital Santa Lúcia o setor de Hotelaria propõe um serviço que atenda o paciente no serviço de quarto, higiene, lavanderia e rouparia. Oferecer condições de conforto, bem-estar, assistência, segurança e qualidade no atendimento é o objetivo do setor, que oferece ainda três auxiliares de higiene, uma camareira e uma assistente de Hotelaria por andar identificada a atividade na figura 6.

Figura 6 - Assistente de Hotelaria e cliente de saúde.

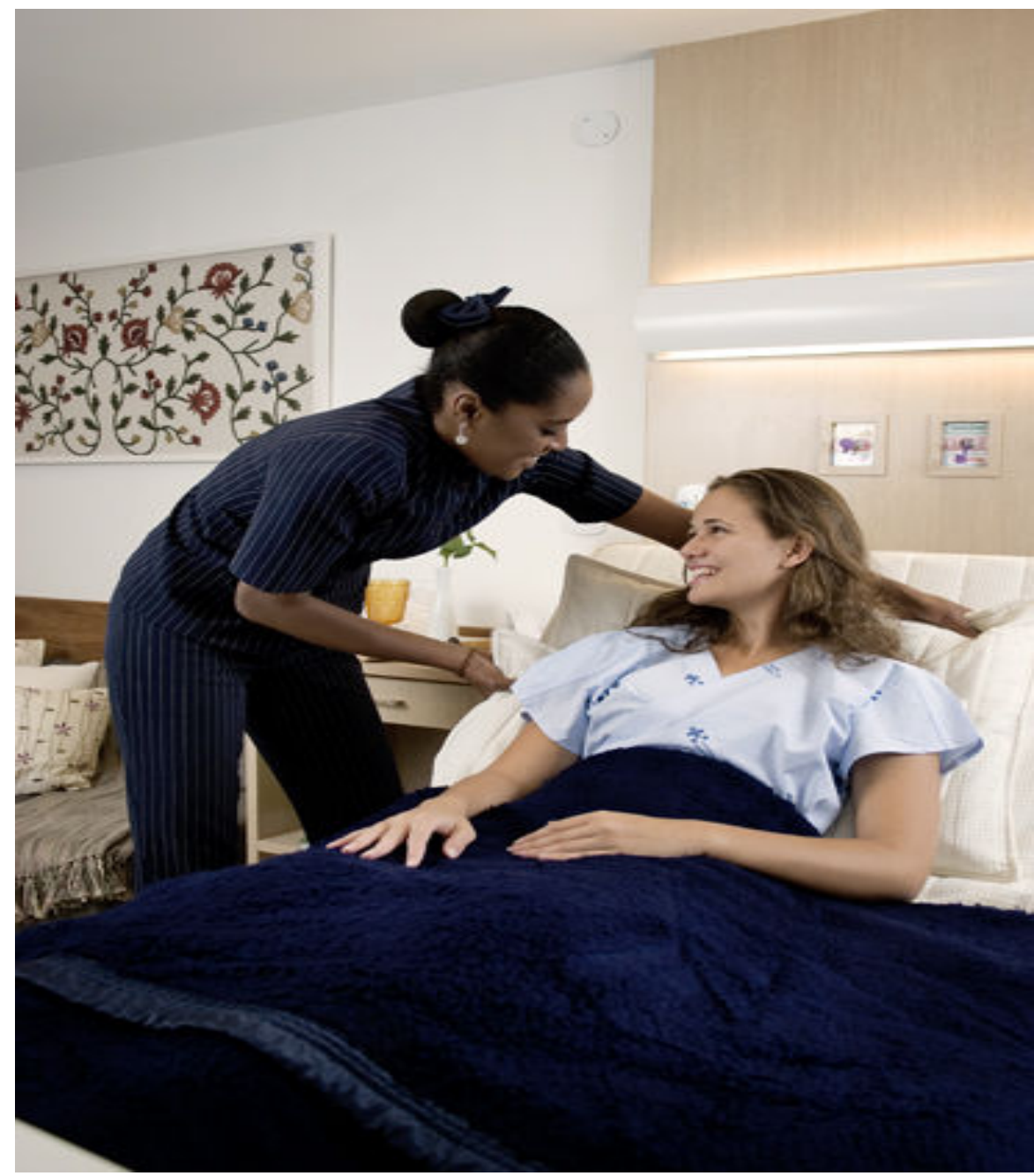

Fonte:www.marliere.com.br/santalucia/pages 
A missão do setor da hotelaria do hospital Santa Lúcia é prestar um serviço padronizado e humanizado, para que o cliente se sinta como uma pessoa respeitada e confiada. Fazer com que os colaboradores trabalhem com amor e desprendimento para que passem que há de melhor ao cliente. Prestar serviços de atendimento ao cliente, acolhendo-o e assistindo-o nas suas necessidades relacionadas à higiene das unidades de internação, ilustrada na figura 7, manutenção da infra-estrutura das acomodações, atendimento diferenciado e suprimento de roupas segundo padrões técnicos de excelência, apoiando a segurança dos processos assistenciais.

Figura 7 - Unidade de Internação - Apartamento tipo "A" - Suíte

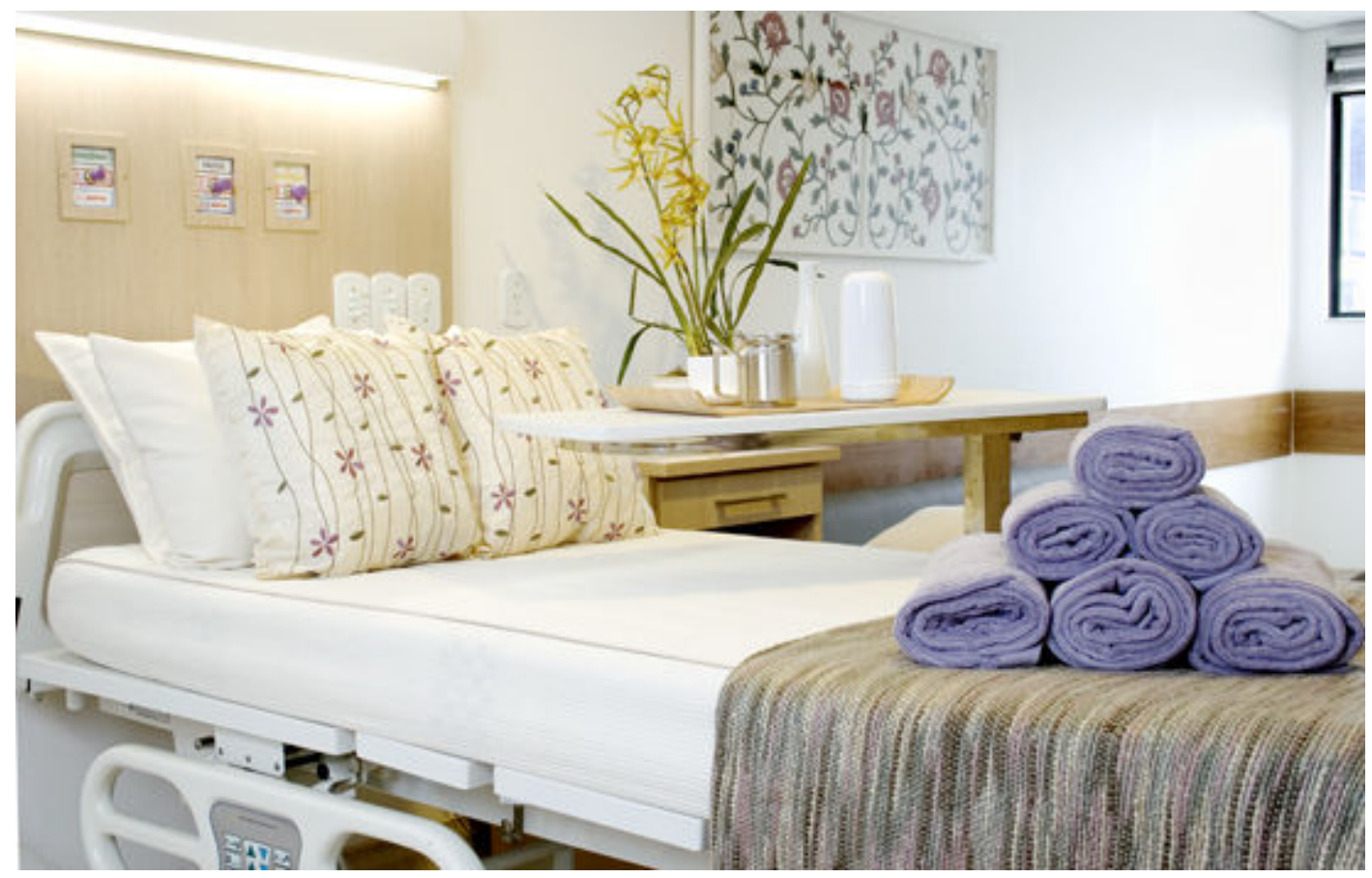

Fonte:www.marliere.com.br/santalucia/pages 


\section{As atribuições do setor de hotelaria do hospital Santa Lúcia são:}

- Planejar, organizar, coordenar e supervisionar todas as etapas da implantação de todos os departamentos da hotelaria;

- Promover a higienização da limpeza terminal e concorrente;

- Fixar um horário para o serviço, em consonância com as atividades desenvolvidas em cada local;

- Dedicar atenção especial ao agendamento de internações;

- Colocar à disposição dos funcionários os manuais específicos de normas e técnicas;

- Observar e avisar os responsáveis, sobre defeitos encontrados em instalações e móveis que são de responsabilidade da hotelaria;

- Distribuir roupa proporcional à necessidade do paciente nos setores responsáveis pela hotelaria; nos horários previamente estabelecidos entre a hotelaria e rouparia;

Os fornecedores do setor de hotelaria é o Setor de compras; Almoxarifado Patrimônio; Recursos Humanos; Manutenção; e Informática. Os principais clientes são os externos, visitante, cliente de saúde, acompanhante, médico; e os clientes internos, que são todos os colaboradores. O principal produto do serviço é fornecer qualidade de higiene e limpeza; e a padronização na arrumação das unidades habitacionais, conforme figura 8. 
Figura 8 - Unidade de Internação - Apartamento tipo "B" - Maternidade

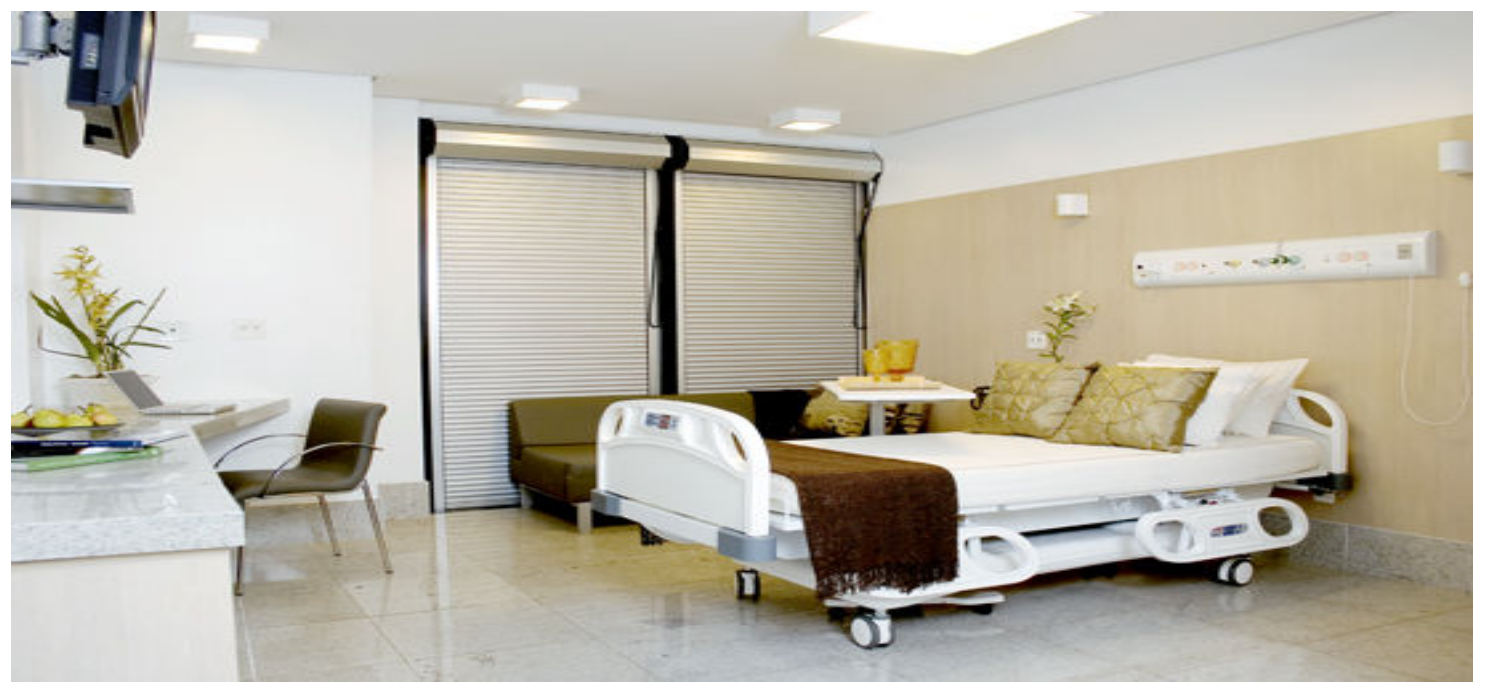

Fonte:www.marliere.com.br/santalucia/pages

Figura 9 - O organograma do setor de hotelaria do Hospital Santa Lúcia é composto por :

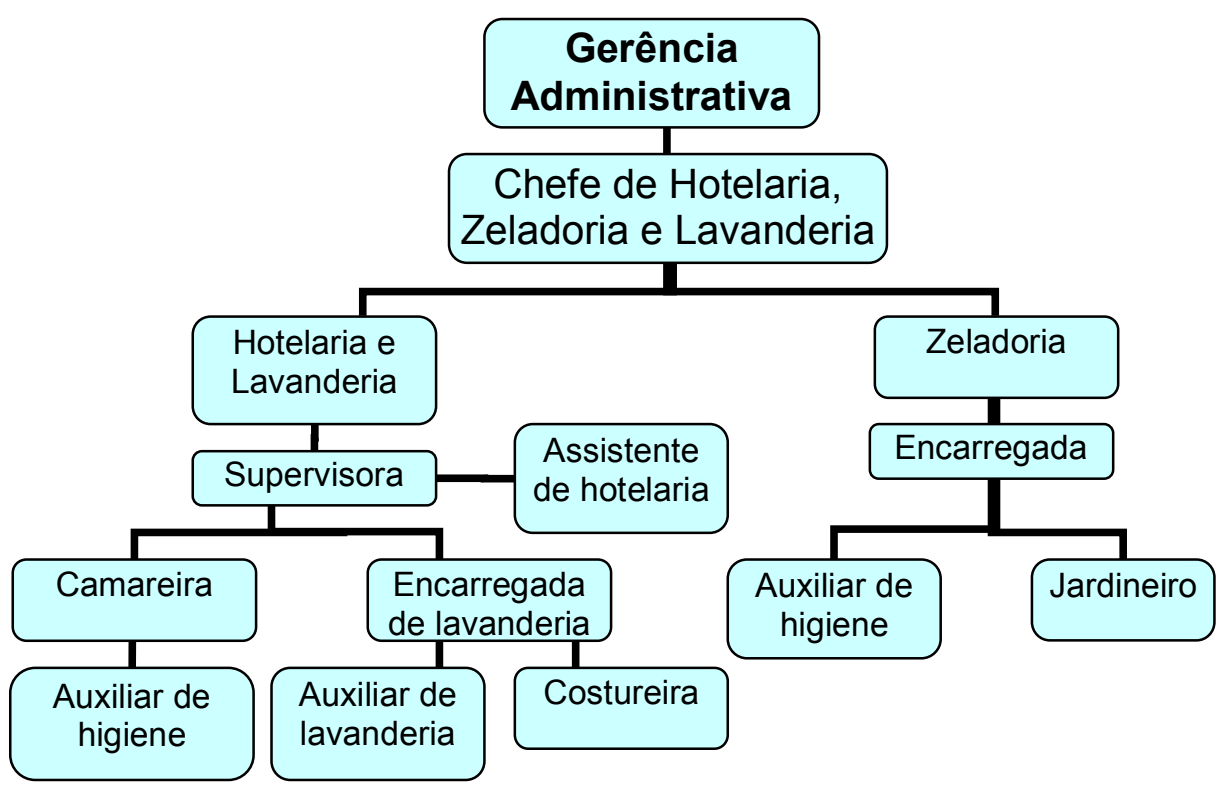


O que é mostrado na estrutura organizacional convencional diferenciada da estrutura do Hospital Santa Lúcia é o responsável da Gerência administrativa, onde fica vinculada a mesma a chefia/área da hotelaria, essa área tem como responsabilidade a área de zeladoria e lavanderia tendo duas subordinações diretas onde deveria ter uma área de governança somente, que é chamado de hotelaria. A mesma é responsável pela área de Lavanderia, Assistentes de hotelaria, Camareiras, e Auxiliares de higiene. A área de zeladoria implica na área de serviços gerais de todo o hospital, bem como áreas comuns, unidades abertas e unidades fechadas. Então o que se sugere dessa estrutura é uma correlação entre a estrutura formal precisando ser reorganizada para dar maior fluidez, facilidades e resultados para a própria execução das tarefas.

\subsection{Funcionamento dos setores:}

\subsubsection{Hotelaria:}

- $\quad$ O Chefe de Hotelaria, Zeladoria e Lavanderia, juntamente com o Supervisor de Hotelaria trabalham alinhados e são os responsáveis em manter o setor em ordem realizando todas as rotinas descritas em planilhas padronizadas;

- A Assistente de hotelaria: colaboradora graduada que é responsável pelo serviço de hotelaria no andar, recebendo o cliente de saúde, realizando o check-in e check-out do apartamento, verificando todos os itens listados dentro da $\mathrm{UH}$; também passa as informações necessárias para o tempo da sua internação, como o uso da TV, roupa de cama, alimentação para o seu acompanhante e demais serviços que o hospital oferece; administra os serviços da camareira que faz o controle da rouparia no andar, acompanhar o serviço da equipe de auxiliares de higiene, priorizando a higienização e liberação dos leitos para futuras internações; faz o controle do uso do EPI 
(Equipamento de Proteção Individual) das colaboradoras. Ainda visita diariamente os pacientes, realizando pesquisa de satisfação com o intuito de ter um feedback dos problemas relacionados aos diversos setores do hospital, repassando-os aos seus responsáveis, buscando da melhor forma possível um retorno positivo a melhoria da Qualidade no atendimento.

\subsubsection{Lavanderia:}

É responsável em realizar a lavagem da roupa de todo o hospital, tanto para as Unidades de internação, quanto para emergência e consultórios. Compõe o setor a Encarregada e Auxiliares de Lavanderia.

\subsubsection{Zeladoria:}

Composta por uma encarregada e seus auxiliares de higiene, o setor cuida das unidades comuns, que são: recepção, radiologia, radioterapia, consultórios, emergência, partes administrativas; os setores fechados (UTI'S, Centro Cirúrgico, CME - Central de material esterilizado, centro obstétrico); jardinagem, controle de pragas e gerenciamento de resíduos;

A encarregada realiza visitas constantes durante o plantão nos diversos setores já citados, fiscalizando o uso correto do EPI e do serviço a serem executados. 


\section{METODOLOGIA}

Para o aprofundamento do tema tratado nesta monografia, foi realizada pesquisa bibliográfica, descrita no referencial teórico deste trabalho.

Vergara (2007) afirma que a pesquisa pode ser dividia em dois critérios básicos: quanto aos fins e quanto aos meios

O presente estudo é dividido da seguinte forma:

- Quanto aos fins, trata-se de pesquisa ou investigação exploratória devido a sua natureza de sondagem ;

- Segundo: quanto aos meios, ou seja, caminho realizado para se chegar as considerações, duas formas de pesquisa foram realizadas:

a) Pesquisa bibliográfica, que é definida por Vergara (2007) "como sendo o estudo sistematizado desenvolvido com base em material publicado em livros, revistas, jornais, redes eletrônicas, isto é, material acessível ao público em geral”

b) Pesquisa documental: que é conceituada pela mesma autora "como sendo a realizada em documentos conservados no interior de órgãos públicos e privados de qualquer natureza, ou com pessoas, registros, anais, regulamentos circulares, ofícios, memorandos, balancetes [...]".

No presente estudo na pesquisa bibliográfica, foram apresentados temas como meios de hospedagem, hotel, sistema de classificação dos meios de hospedagem; hospital; acreditação, hotelaria hospitalar, matriz de classificação hotelaria hospitalar, serviços compatíveis, padronização, indicadores, qualidade, qualidade na prestação de serviços, descrição dos serviços prestados na hotelaria hospitalar no Hospital Santa Lúcia. 
Através da pesquisa exploratória foi possível realizar a análise na matriz de classificação hotelaria hospitalar na Instituição privada Santa Lúcia (apêndice). O método utilizado foi o observacional, esse método é o mais utilizado nas ciências sociais e apresenta alguns aspectos curiosos, pode ser considerado como o mais primitivo, ou também um dos mais modernos. (Gil 2007). A pesquisa documental foi feita através de registros fotográficos.

A pesquisa foi realizada a partir da técnica de observação direta da matriz de classificação da hotelaria hospitalar, instrumento composto de requisitos para classificação e padrões de serviços e produtos do empreendimento. A matriz apresentada é estruturada de dezessete em grupos distribuídos em 142 itens adaptados para a hotelaria hospitalar, a saber: Posturas Legais; Segurança; Saúde e Higiene; Conservação e Manutenção; Atendimento ao Hóspede; Portaria e Recepção; Acesso e circulações; Setor habitacional; Áreas sociais; Comunicações; Alimentos e bebidas; Lazer; Eventos; Serviços Adicionais; Ações ambientais; Médico; Informática e Comercial. O que a matriz traz como indicadores nos referidos itens são os elementos que servem como padrões mínimos ${ }^{10}$ de qualidade a serem seguidos.

Foi adotada a seguinte indicadores/classificação para determinar os padrões de serviços a partir da matriz de classificação da Hotelaria Hospitalar.

\section{Quadro 1 - Indicadores de padrões de serviços}

\begin{tabular}{|l|c|l|l|}
\hline \multicolumn{1}{|c|}{ Status } & Prioridade & \multicolumn{1}{|c|}{ Especificações } & Diferenças Específicas \\
\hline NR & $*$ & Não recomendável & Padrão de serviço/produto \\
\hline
\end{tabular}

\footnotetext{
${ }^{10}$ São padrões de serviços/produtos adequados em relação às tarifas praticadas, perfil de clientes.
} 


\begin{tabular}{|l|l|l|l|}
\hline & & & $\begin{array}{l}\text { não adequado em relação às } \\
\text { tarifas praticadas, perfil de } \\
\text { clientes e ambientação. }\end{array}$ \\
\hline C & $*$ & Conforme & $\begin{array}{l}\text { Manter padrão definido na } \\
\text { Instituição. }\end{array}$ \\
\hline NC & $*$ & Não Conforme & Fora dos padrões desejáveis. \\
\cline { 2 - 3 } & + & Não Conforme Prioritário & $\downarrow$ \\
& & & \\
\hline
\end{tabular}

Foram realizadas visitas técnicas no mês de maio de 2009, no Hospital Brasília, e no Hospital das Forças Armadas onde foram identificadas práticas e serviços da Hotelaria Hospitalar. 


\section{APRESENTAÇÃo E ANÁLISE DE RESULTADOS}

Este estudo tem como finalidade apresentar os dados da pesquisa realizada, explorada de acordo com o referencial teórico elaborado e a partir do instrumento de coleta de dados - matriz de classificação hoteleira adaptada a hotelaria hospitalar.

Desta forma, conforme proposto na metodologia, serão expostos os resultados através da pesquisa bibliográfica e documental, e da técnica de observação direta da matriz.

Neste primeiro momento, serão apresentados os aspectos da estrutura organizacional, por meio do qual se buscou apresentar as paridades entre hotel e hospital e as possibilidades de serviços. Para Boeger (2005) a hotelaria hospitalar é a reunião de todos os serviços de apoio, que, associados aos serviços específicos, oferecem aos clientes internos e externos, conforto, segurança e bem-estar durante seu período de internação.

A partir da estrutura organizacional de um hotel tradicional e de um hospital, buscou-se conhecer as áreas comuns e identificar as similaridades dos serviços possibilitando a transferência desse desenho para a hotelaria hospitalar.

Conforme atesta Castelli (2001) a relação do organograma do hotel está baseada na relação de um sistema, composta de vários subsistemas ou áreas, e cada uma dessas áreas podem sofrer uma divisão ainda maior, destacando a área de hospedagem, composta por recepção, telefonia e governança. Essas áreas são denominadas de Unidades Gerenciais Básicas - UGBs, e é no interior de cada uma delas que as pessoas executam suas tarefas ou realizam as suas atividades. 
No organograma do hospital destaca-se o componente de Staff, (Recursos Humanos) de acordo com Stephen (1999), é o grupo onde proporciona os elementos necessários nas tomadas de decisões por parte da gestão de uma empresa fragmentadas em relação à estrutura tradicional. Já no organograma da hotelaria hospitalar esta visão vai de encontro à opinião dos autores Boeger (2005) e Taraboulsi (2006), que mostra o conjunto de serviços oferecidos que vão desde a o setor de atendimento, governança, serviços de nutrição e dietética, segurança patrimonial à manutenção.

Percebe-se a existência de uma ligação muito grande da estrutura da hotelaria tradicional comparada com a estrutura na área de saúde, prioritariamente, entre os setores que envolvem a área de hospedagem, ou seja, recepção e governança. Figura 1 - Gerência de Hotelaria

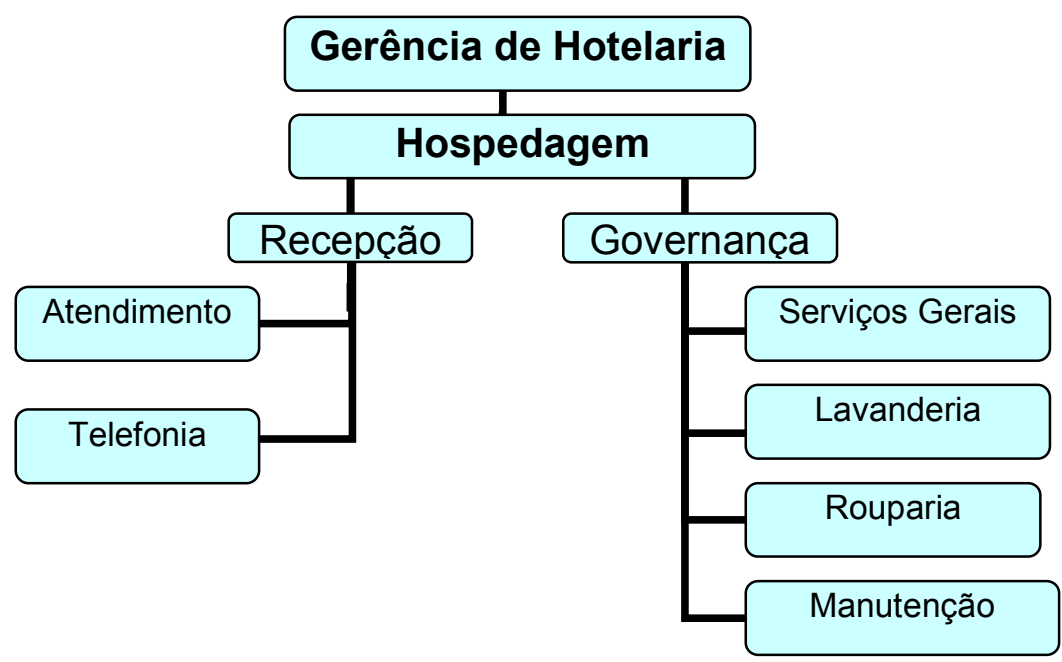


A pesquisa foi realizada a partir da técnica de observação direta da matriz de classificação da hotelaria hospitalar.

No contexto da área de hospedagem, o setor que se mostra de forma mais dominante, tendo como referência o Hospital Santa Lucia é a área de governança. No estudo documental realizado nesta unidade de saúde foi possível identificar que o setor de hotelaria o qual se insere a área de governança é composto pelo chefe do setor, supervisora, assistentes de andar, camareiras e auxiliares de higiene, contando com todo o apoio da área de lavanderia que envolve encarregada, auxiliares de lavanderia e costureira.

Os itens priorizados neste estudo foram àqueles pertinentes ao setor de governança:

Quadro 1 - Saúde/Higiene:

\begin{tabular}{|l|l|l|}
\hline \multicolumn{1}{|c|}{ ITENS GERAIS } & \multicolumn{1}{|c|}{ OBSERVAÇÕES } & STATUS \\
\hline pigiene do ambiente, das & Realizam-se rotina diária nas & Conforme \\
& áreas comuns do hospital, & \\
& setores fechados (UT'I, & \\
& Obstétrico), e unidades & \\
& abertas (apartamentos). & \\
\hline
\end{tabular}

Quadro 2 - Conservação/Manutenção; 


\begin{tabular}{|l|l|l|}
\hline Todas as áreas, & Todas as áreas, & Conforme \\
equipamentos e instalações & equipamentos e instalações & \\
conservação/manutenção & quando não, realiza-se & imediatamente o reparo dos \\
& danos. & \\
\hline
\end{tabular}

Quadro 3 - Acesso/Circulações;

\begin{tabular}{|l|l|l|}
\hline \multicolumn{1}{|c|}{ ITENS GERAIS } & \multicolumn{1}{|c|}{ OBSERVAÇÕES } & STATUS \\
\hline Áreas adequadas e & Existem placas de & Conforme \\
circulação fáceis e & identificação como acesso a & \\
desimpedidos nas & rampas, setores e as & \\
dependências do & diversas áreas. & \\
estabelecimento, inclusive & & \\
para pessoas portadoras de & & \\
deficiência física e/ou com & & Conforme \\
necessidades especiais & & \\
\hline Entrada de serviço - & Todas as entradas são & \\
colaboradores, maternidade & distintas & \\
e óbitos. & & \\
\hline Identificação do sistema & Existe identificação & \\
sinalização externa. & adequada & \\
\hline
\end{tabular}




\begin{tabular}{|l|l|l|}
\hline Identificação do sistema & Existe identificação & Conforme \\
sinalização interna. & adequada & \\
\hline
\end{tabular}

\section{Quadro 4 - Setor Habitacional;}

\begin{tabular}{|c|c|c|}
\hline $\begin{array}{l}\text { Apartamentos ( Suíte, Luxo, } \\
\text { Executivos e Standard) }\end{array}$ & $\begin{array}{l}\text { O Hospital dispõe de Suítes } \\
\text { VIP’s, Apartamentos e } \\
\text { Enfermarias. }\end{array}$ & Conforme \\
\hline $\begin{array}{l}\text { UH do tipo suíte e/ou } \\
\text { unidades conversíveis em } \\
\text { suítes }\end{array}$ & $\begin{array}{l}\text { Não dispõe de sistema de } \\
\text { conversão de suítes. }\end{array}$ & Não Conforme \\
\hline $\begin{array}{l}\text { Rouparias auxiliares no } \\
\text { setor habitacional }\end{array}$ & $\begin{array}{l}\text { Cada andar contém um } \\
\text { armário de rouparia sob } \\
\text { responsabilidade da } \\
\text { Hotelaria. }\end{array}$ & Conforme \\
\hline $\begin{array}{l}\text { Local específico para } \\
\text { material de limpeza }\end{array}$ & $\begin{array}{l}\text { Cada andar contém um } \\
\text { depósito de material de } \\
\text { limpeza (DML). }\end{array}$ & Conforme \\
\hline $\begin{array}{l}\text { Climatização adequada em } \\
100 \% \text { das UH }\end{array}$ & $\begin{array}{l}\text { Ar condicionado em todos } \\
\text { os apartamentos. }\end{array}$ & Conforme \\
\hline $\begin{array}{l}\text { TV a cores, equipamento } \\
\text { de vídeo cassete e DVD em } \\
100 \% \text { das UH, com TV por }\end{array}$ & $\begin{array}{l}\text { As UH’s não dispõe de } \\
\text { vídeo cassete nem DVD, } \\
\text { que é de suma importância. }\end{array}$ & Não Conforme \\
\hline
\end{tabular}




\begin{tabular}{|l|r|r|}
\hline assinatura a cabo ou por & & \\
antena parabólica. & A UH disponibiliza TV em & Conforme \\
UH, com TV por assinatura & cores com serviços de & \\
a cabo ou por antena & assinatura a cabo. & \\
parabólica & Codas as UH dispõe de TV & \\
\hline TV em 100\% das UH & comum, os Apt. & \\
& Reformados agora terão TV & \\
\hline Mini refrigerador em 100\% & Dispõe em 100\% das UH & Conforme \\
das UH & & \\
\hline
\end{tabular}

Baseada nos indicadores de (Não recomendável - NR; Conforme- C e Não conforme - NC) destacamos a análise acima do hospital Santa Lúcia a partir da matriz de classificação hoteleira no quadro 5:

Quadro 5 - Resumo dos ITENS ESPECÍFICOS da análise em destaque

\begin{tabular}{|l|c|c|c|c|}
\hline Resumo & NR & C & NC+ & Total Avaliado \\
\hline Acessos e Circulações & 0 & 4 & 0 & 4 \\
\hline Setor Habitacional & 2 & 7 & 0 & 9 \\
\hline Saúde / Higiene & 0 & 1 & 0 & 1 \\
\hline Conservação e Manutenção & 0 & 1 & 0 & 1 \\
\hline
\end{tabular}


Gráfico 1 - Demonstração dos indicadores dos ÍTENS ESPECíFICOS a partir da matriz de classificação aplicada no Hospital Santa Lúcia.

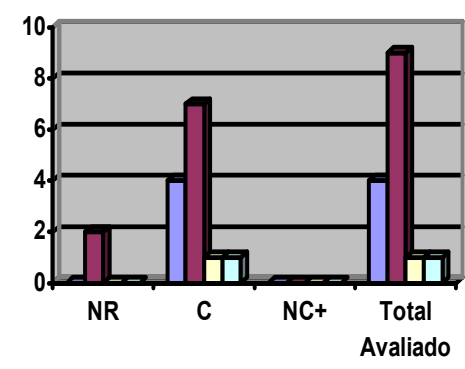

\begin{tabular}{|l|}
\hline Acessos e Circulações \\
QSetor Habitacional \\
Saúde / Higiene \\
Conservação e \\
Manutenção
\end{tabular}

Quadro 6 - Resumo dos ITENS GERAIS da análise

\begin{tabular}{|l|c|c|c|c|}
\hline Resumo Geral Matriz & NR & C & NC+ & Total Avaliado \\
\hline Acessos e Circulações & 0 & 5 & 0 & 5 \\
\hline Setor Habitacional & 8 & 34 & 0 & 42 \\
\hline Saúde / Higiene & 0 & 1 & 0 & 1 \\
\hline Conservação e Manutenção & 0 & 1 & 0 & 1 \\
\hline
\end{tabular}

Gráfico 2 - Demonstração dos indicadores dos ÍTENS GERAIS a partir da matriz de classificação aplicada no Hospital Santa Lúcia.
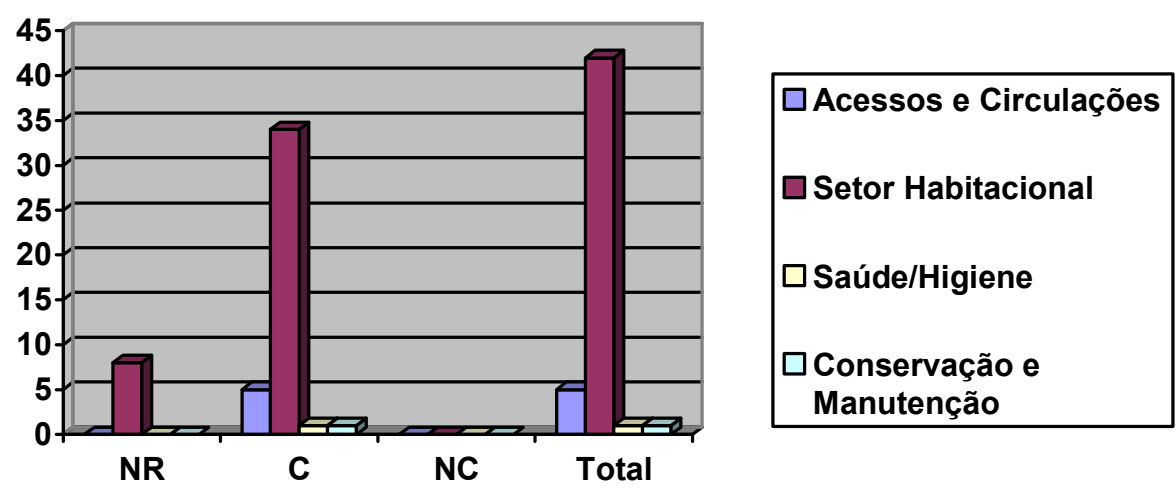

Numa análise preliminar dos dados que nos trazem a aplicação da matriz no hospital Santa Lúcia mostra: 
Para se obter o padrão mínimo desejável, os itens "Conforme" devem ser representativos na matriz de classificação. A mínima incidência de itens "Não Conforme" confirma que a matriz de classificação hoteleira não está alinhada com os padrões de serviços determinados.

Concluindo, faz-se necessário a ampliação dos itens que apresentam conformidade permitindo assim a reaplicação da matriz de classificação e a manutenção de um padrão mínimo de produtos e serviços, oferecendo o bem estar para os clientes, podendo ser utilizados como diferencial em uma estrutura de serviços hoteleiros em um hospital.

Percebe-se também que há o grande número de itens que estão em desenvolvimento na área de serviços, na área hospitalar existem vários que dão apoio com suas atividades meio e fim, as equipes de recepção e internação; emergência, enfermagem; nutrição e dietética; segurança patrimonial e manutenção O que se vê nas instituições que mais deixa a desejar são aspectos como organização, atendimento adequado, cortesia e respeito.

Com o propósito de trazer à luz as particularidades complementares a este estudo buscou-se enfatizar a importância da qualidade dos serviços, prioritariamente, na utilização de indicadores que leva a padronização dos serviços prestados pela hotelaria.

Após conhecer a estrutura organizacional das instituições de saúde privada Brasília, Santa Lúcia e público Hospital das Forças Armadas, concluem-se então que foram identificados os serviços e elementos similares da hotelaria tradicional, 
selecionando os indicadores prioritários para fim levar a padronização dos serviços para a hotelaria hospitalar. 


\section{CONSIDERAÇÕES FINAIS}

A partir do estudo realizado verificou-se que a hotelaria hospitalar iniciou a partir da caracterização do conceito dos meios de hospedagem e sua interface com unidades habitacionais, fazendo o uso de padrões definidos aos sistemas de classificação dos meios de hospedagem utilizados na hotelaria tradicional. O hospital, por sua vez adotou o sistema de acreditação.

A hotelaria hospitalar, segundo Tarabousi (2006), vem despertar os serviços de hotelaria implantada e adaptada no ambiente hospitalar precisando serem identificados; para isso; há a necessidade de lhes dar identidade própria para que possa ser distinguidos dos demais serviços hospitalares, ocupando seu espaço no organograma geral e, conseqüentemente, serem percebidos pelos clientes de saúde. Nada melhor que departamentalização para tornar esses serviços visíveis, agrupandoos em unidades organizacionais, de acordo com um critério específico de homogeneidade.

O principal objetivo desse estudo é identificar e elencar a estrutura organizacional de uma instituição de saúde a partir da padronização dos serviços utilizando os indicadores da hotelaria tradicional como fator resultante de qualidade. Foram identificados e levantados na área de governança e recepção a grande demanda nos serviços com interfaces e similaridades tanto para a Hotelaria tradicional como para a Hotelaria Hospitalar. Segundo ainda nos organogramas apresentados pelos autores Taraboulsi e Boeger percebe-se que ambos destacam a Gerência de Hotelaria, especificando as áreas de governança; de $A \& B$, de Recepção como imprescindíveis no funcionamento da Hotelaria hospitalar, em destaque para a área de segurança e 
patrimonial, que na estrutura apresentada por Taraboulsi está diluída em todas as áreas. A metodologia da pesquisa foi exploratória utilizando-se do método observacional no setor habitacional do hospital Santa Lúcia, fazendo uso da matriz de classificação da hotelaria hospitalar para trazer a luz o desenho de uma estrutura organizacional mínima que indique possibilidades de adoção de um padrão de serviços a partir de indicadores.

Nota-se que há uma similaridade na estrutura organizacional e níveis hierárquicos: Diretoria, Gerência, Supervisão, Assistência da hotelaria hospitalar, elencados na estrutura orgânica da instituição de saúde a partir de indicadores: Saúde e Higiene; Conservação e Manutenção; Acesso e circulações; e Setor habitacional; que podem levar a uma padronização de serviços.

No contexto geral, os indicadores são utilizados como ferramentas para o desenho e adoção de um padrão de serviços, fazendo a grande diferença para a hotelaria hospitalar. A adoção de uma padronização em uma Unidade Habitacional ou em um setor, propriamente, setor de governança, agrega valor aos serviços prestados refletindo a qualidade do atendimento, facilitando o desempenho da equipe de saúde e de forma integrada trazendo uma maior assistência.

Foi possível identificar também na estrutura organizacional da hotelaria tradicional, os staffs similares, quando comparado com as instituições privadas de saúde. Observando os staffs na hotelaria tradicional que tenha interface na estrutura organizacional da área de saúde, buscou-se destacar hierarquias que podem ser adotadas em uma estrutura da hotelaria hospitalar.

Constatou-se que falar sobre a hotelaria hospitalar não é uma tarefa fácil, sabendo da inexistência da variedade bibliográfica e o número reduzido de hospitais em 
Brasília que buscam iniciativas na implantação da hotelaria hospitalar, trazendo diferenciais em seus serviços.

Quando se determina a padronização de um serviço, definiram-se também indicadores que possibilitam monitorar e estabelecer controles de qualidade e pode também interferir diretamente no desenho da estrutura organizacional de uma instituição. 
- BOEGER, Marcelo Assad. Gestão em hotelaria hospitalar / Marcelo Assad Boeger. 2 ed. São Paulo: Atlas, 2005.

- BRASIL, Ministério da Saúde. Secretaria de Assistência à Saúde. Departamento de Sistemas e Redes Assistenciais. Manual Brasileiro de Acreditação Hospitalar / Secretaria de Assistência à Saúde, Departamento de Sistemas e Redes Assistenciais. 3 ed.- Brasília: Ministérios da Saúde, 2001.

- CASTELLI, Geraldo: Administração hoteleira. / Geraldo Castelli. 9. ed. Caxias do Sul: EDUCS, 2001.

- CASTELLI, Geraldo: Excelência em hoteleira: uma abordagem prática. / Geraldo Castelli. Rio de janeiro: Qualitymark. Ed. 2002.

- DUARTE, Vladir Vieira. Administração de sistemas hoteleiros / Vladir Vieira Duarte. São Paulo: Senac, 1996.

- GHELLE, Janete Lucia Possato. A humanização hospitalar no hospital Ministro Costa Calvante. Saúde Business web, 2005. Disponível em HTTP:// www.saúdeusinessweb.com.br sbw_artigo. vxlpu? id=87697>acesso em 2009.

- GODOI, Adalto Feliz de. Hotelaria hospitalar e humanização no atendimento em hospitais: pensamento e fazendo/Adalto Feliz de Godoi. São Paulo: Ícone, 2004.

- INGRAN, S. Medlik. Introdução à Hotelaria: Gerenciamento e Serviços/ S. Medlik Ingran. Tradução(da 4. ed. Original) Fabiola de Carvalho S. Vasconcelos - Rio de Janeiro: Campus, 2002.

- LAKATOS, Eva Maria. Metodologia do trabalho cientifico: procedimentos básicos, pesquisa bibliográfica, projeto e relatórios, publicações e trabalhos científicos / Marina de Andrade Marconi, Eva Maria Lakatos, $6^{\circ}$ ed. São Paulo: Atlas, 2001. 
- LAMPRECHT, James e Ricci, Renato. Padronizando o sistema da qualidade na hotelaria mundial /James Lamprecht e Renato Licci. Rio de Janeiro: Qualitymark Ed., 1997.

- LONGANESE, Luiz André. Direito aplicado à hotelaria. / Luiz André Longanese. Campinas, SP: Papirus, 2004. (Série Hospitalidade).

- MARQUES, J. Albano. Introdução à Hotelaria / J. Albano Marques. Bauru. São Paulo: EDUSC, 2003.

- NORMAS da ABNT. Disponível em: <http://www.firb.br/abntmonograf.htm> . Acesso em: 02 jul. 2009.

- PETROCCHI, Mario: Hotelaria: Planejamento e gestão/ Mário Petrocchi. São Paulo: Futura, 2002.

- ROBBINS, Stephen P. Comportamento Organizacional. 8. Ed. Rio de Janeiro, 1999.

- TARABOULSI, Fadi Antoine: Administração de hotelaria hospitalar: serviços aos clientes, humanização do atendimento, departamentalização, gerenciamento, saúde e turismo, hospitalidade. Tecnologia de informação. Fadi Antonie Taraboulsi, $3^{\circ}$ ed. São Paulo: Atlas, 2006.

- VERgARA, Sylvia Constant. Projetos e Relatórios de Pesquisa em Administração / Sylvia Constant Vergara. - 9 ed. - São Paulo: atlas, 2007. 
11 APÊNDICE

Matriz de Classificação da Hotelaria Hospitalar aplicada no hospital privado Santa Lúcia 


\section{Avaliacão Padroes Mínimos Hotelaria Hospitalar - Itens Gerais - HOSPITAL SANTA LÚCIA}

\begin{tabular}{|c|c|c|c|c|c|c|c|c|c|c|c|c|}
\hline \multirow{2}{*}{1} & \multirow{2}{*}{ ITENS GERAIS } & \multirow{2}{*}{ OBSERVAÇÕES } & \multicolumn{3}{|c|}{ CLASSIFICAÇAO } & \multirow{2}{*}{$\begin{array}{l}\text { ORIENTAÇÕES PARA O PLANO } \\
\text { DE AÇÃO }\end{array}$} & \multirow{2}{*}{ Resp } & \multirow{2}{*}{$\begin{array}{l}\text { DEPARTAMENTOS } \\
\text { ENVOLVIDOS }\end{array}$} & \multicolumn{2}{|c|}{ Quando } & \multirow{2}{*}{$\begin{array}{c}\text { RESULTADO } \\
\text { AVALIAÇÃO FINAL }\end{array}$} & \multirow[t]{2}{*}{ OBS. } \\
\hline & & & NR & C & NC & & & & Início & Prazo & & \\
\hline 1.1 & \multicolumn{2}{|l|}{ POSTURAS LEGAIS } & & & & & & & & & & \\
\hline 1.1 .2 & $\begin{array}{c}\text { Legislação quanto à proteção contra incêndio, dispondo } \\
\text { de equipamentos e instalações exigidos pelas } \\
\text { autoridades competentes e prevendo rotas de fuga, } \\
\text { iluminação de emergência e providências em situações } \\
\text { de pânico }\end{array}$ & & & & & & & Comunicação & & & & \\
\hline \multirow[t]{7}{*}{1.1 .4} & $\begin{array}{c}\text { Exigências da EMBRATUR, constantes da legislação de } \\
\text { turismo }(\mathrm{H}) \text { e internação }(\mathrm{HH}) \text {, referentes a: }\end{array}$ & & & & & & & & & & & \\
\hline & $\begin{array}{l}\text { a) registro do hóspede(H) ou paciente saúde }(\mathrm{HH}) \text {, por } \\
\text { intermédio de Ficha Nacional de Registro de Hóspedes - } \\
\text { FNRH }\end{array}$ & & & & & & & $\begin{array}{c}\text { Gerente de Hotelaria } \\
\text { Recepção e Reservas } \\
\text { Pronto de Socorro }\end{array}$ & & & & \\
\hline & $\begin{array}{l}\text { b) fornecimento mensal do Boletim de Ocupação } \\
\text { Hoteleira - BOH }(H) \text {; Envio ao Ministério da Saúde }(H H) \text {. }\end{array}$ & & & & & & & $\begin{array}{c}\text { Gerente de Hotelaria } \\
\text { Dep. Recepção e } \\
\text { Reservas }\end{array}$ & & & & \\
\hline & $\begin{array}{l}\text { c) fornecimento de Cartão do Estabelecimento com o } \\
\text { nome do hóspede e período de hospedagem }\end{array}$ & & & & & & & \begin{tabular}{|c|} 
Gerente de Hotelaria \\
Recepção e Reservas \\
Pronto de Socorro
\end{tabular} & & & & \\
\hline & $\begin{array}{l}\text { e) divulgação e explicitação dos compromissos } \\
\text { recíprocos para com o hóspede através de: }\end{array}$ & & & & & & & & & & & \\
\hline & $\begin{array}{l}\text { e.1) Regulamento Interno, com direitos e deveres do } \\
\text { hóspede }\end{array}$ & & & & & & & \multirow{2}{*}{ Comunicação } & & & & \\
\hline & $\begin{array}{l}\text { e.2) Serviços e preços oferecidos, incluídos, ou não, na } \\
\text { diária, divulgados na forma da legislação }\end{array}$ & & & & & & & & & & & \\
\hline & $\begin{array}{l}\text { f) Meios para pesquisar opiniões e reclamações dos } \\
\text { hóspedes e solucioná-las }\end{array}$ & & & & & & & $\begin{array}{l}\text { Comunicação/ } \\
\text { Ouvidoria }\end{array}$ & & & & \\
\hline \multirow[t]{2}{*}{1.1 .5} & $\begin{array}{c}\text { Facilidades construtivas, de instalações e de uso, para } \\
\text { pessoas com necessidades especiais, de acordo com a } \\
\text { NBR } 9050 \text { - 1994, em prédio com projeto de arquitetura } \\
\text { aprovado pela Prefeitura Municipal, como meio de } \\
\text { hospedagem, após } 12 \text { de agosto de } 1987 .\end{array}$ & & & & & & & \multirow[t]{2}{*}{\begin{tabular}{|c|} 
Diretor ADM \\
Diretor Financeiro \\
Gerente de Hotelaria
\end{tabular}} & & & & \\
\hline & $\begin{array}{l}\text { NOTA: No caso de projetos anteriores, o meio de } \\
\text { hospedagem deverá dispor de sistema especial de } \\
\text { atendimento. }\end{array}$ & & & & & & & & & & & \\
\hline 1.2 .1 & Meios para controle do uso dos cofres & & & & & & & $\begin{array}{c}\text { Diretor ADM; Gerente } \\
\text { de Hotelaria }\end{array}$ & & & & \\
\hline
\end{tabular}




\begin{tabular}{|c|c|c|c|c|c|c|c|c|c|c|c|c|}
\hline \multirow{2}{*}{1} & \multirow{2}{*}{ ITENS GERAIS } & \multirow{2}{*}{ OBSERVAÇÕES } & \multicolumn{3}{|c|}{ CLASSIFICAÇAO } & \multirow{2}{*}{$\begin{array}{c}\text { ORIENTAÇÕES PARA O PLANO } \\
\text { DE AÇÃO }\end{array}$} & \multirow{2}{*}{ Resp } & \multirow{2}{*}{$\begin{array}{l}\text { DEPARTAMENTOS } \\
\text { ENVOLVIDOS }\end{array}$} & \multicolumn{2}{|c|}{ Quando } & \multirow{2}{*}{$\begin{array}{c}\text { RESULTADO } \\
\text { AVALIAÇÃO FINAL }\end{array}$} & \multirow[t]{2}{*}{ OBS. } \\
\hline & & & NR & C & NC & & & & Início & Prazo & & \\
\hline 1.2.2 & Circuito interno de TV ou equipamento de segurança & & & & & & & $\begin{array}{c}\text { Gerente de Infra- } \\
\text { estrutura/ Gerente de } \\
\text { Hotelaria }\end{array}$ & & & & \\
\hline 1.2.4 & $\begin{array}{l}\text { Rotas de fuga sinalizadas nas áreas sociais e } \\
\text { restaurantes }\end{array}$ & & & & & & & Comunicação & & & & \\
\hline \multirow[t]{3}{*}{1.2 .5} & $\begin{array}{c}\text { Serviço de segurança no estabelecimento, por intermédio } \\
\text { de: }\end{array}$ & & & & & & & & & & & \\
\hline & $\begin{array}{l}\text { a) pessoal com formação adequada, próprio ou } \\
\text { contratado, e com dedicação exclusiva }\end{array}$ & & & & & & & Gerente de Infra- & & & & \\
\hline & b) porteiro (admite-se acúmulo de funções) & & & & & & & $\begin{array}{c}\text { Hotelaria } \\
\end{array}$ & & & & \\
\hline \multirow[t]{2}{*}{1.2 .6} & $\begin{array}{l}\text { Preparo para lidar com situações de incêndio e pânico } \\
\text { (assalto, explosão, inundação e outros) }\end{array}$ & & & & & & & & & & & \\
\hline & $\begin{array}{c}\text { a) com equipes predeterminadas, com treinamento } \\
\text { específico (Brigadas) }\end{array}$ & & & & & & & \begin{tabular}{|c|} 
Gerente de Infra- \\
\end{tabular} & & & & \\
\hline 1.2.7 & Cobertura contra roubos, furtos e responsabilidade civil & & & & & & & $\begin{array}{c}\text { Gerente de Infra- } \\
\text { estrutura/ Gerente de } \\
\text { Hotelaria }\end{array}$ & & & & \\
\hline 1.3 & \multicolumn{2}{|l|}{ SAÚDE / HIGIENE } & & & & & & & & & & \\
\hline 1.3.4 & Higiene do ambiente, das pessoas e dos serviços & \begin{tabular}{|c|} 
Realiza-se rotinas diárias nas área \\
comuns do hospital, setores \\
fechados (UT'I, Centro Cirúrgico, \\
Centro Obstétrico, e unidades \\
abertas(apartamentos)
\end{tabular} & & $\mathrm{x}$ & & & & \begin{tabular}{|c|} 
Gerente de Infra- \\
estrutura; Governanta; \\
Gerente de Hotelaria
\end{tabular} & & & & \\
\hline 1.4 & \multicolumn{2}{|l|}{ CONSERVAÇÃO / MANUTENÇÃO } & & & & & & & & & & \\
\hline 1.4.1 & $\begin{array}{l}\text { Todas as áreas, equipamentos e instalações em } \\
\text { condições adequadas de conservação/manutenção }\end{array}$ & \begin{tabular}{|} 
Todas as áreas, \\
equipamentos e \\
instalações sempre estão \\
adequados, quando não, \\
realiza-se imediatamente o \\
reparo dos danos.
\end{tabular} & & $x$ & & & & \begin{tabular}{|c|} 
Gerente de Infra- \\
estrutura; Governanta; \\
Gerente de Hotelaria
\end{tabular} & & & & \\
\hline
\end{tabular}




\begin{tabular}{|c|c|c|c|c|c|c|c|c|c|c|c|c|}
\hline \multirow{2}{*}{1} & \multirow{2}{*}{ ITENS GERAIS } & \multirow{2}{*}{ OBSERVAÇÕES } & \multicolumn{3}{|c|}{ CLASSIFICAÇAO } & \multirow{2}{*}{\begin{tabular}{|c|} 
ORIENTAÇÕES PARA O PLANO \\
DE AÇÃO
\end{tabular}} & \multirow{2}{*}{ Resp } & \multirow{2}{*}{$\begin{array}{l}\text { DEPARTAMENTOS } \\
\text { ENVOLVIDOS }\end{array}$} & \multicolumn{2}{|c|}{ Quando } & \multirow{2}{*}{$\begin{array}{c}\text { RESULTADO } \\
\text { AVALIAÇÃO FINAL }\end{array}$} & \multirow{2}{*}{ OBS. } \\
\hline & & & NR & C & NC & & & & Início & Prazo & & \\
\hline 1.5 .1 & $\begin{array}{l}\text { Instalações e equipamentos com nível de sistemas } \\
\text { capazes de assegurar maior comodidade aos hóspedes }\end{array}$ & & & & & & & \begin{tabular}{|c|} 
Diretor ADM \\
Diretor Financeiro \\
Gerente de Hotelaria
\end{tabular} & & & & \\
\hline 1.5 .2 & Abertura de cama & & & & & & & $\begin{array}{l}\text { Gerente de Negócios; } \\
\text { Gerente de Hotelaria }\end{array}$ & & & & \\
\hline 1.5 .3 & $\begin{array}{c}\text { Disponibilização gratuita em } 100 \% \text { das unidades de cesta } \\
\text { de frutas e/ou outras cortesias especiais }\end{array}$ & & & & & & & $\begin{array}{l}\text { Gerente de Negócios; } \\
\text { Gerente de Hotelaria }\end{array}$ & & & & \\
\hline 1.5 .5 & $\begin{array}{l}\text { Procedimento para atendimento especial para } \\
\text { autoridades e personalidades }\end{array}$ & & & & & & & $\begin{array}{c}\text { Diretor ADM Gerente } \\
\text { de Hotelaria }\end{array}$ & & & & \\
\hline 1.5 .6 & $\begin{array}{c}\text { Facilidades de atendimento para minorias especiais } \\
\text { (fumantes, idosos, pessoas portadoras de deficiências } \\
\text { físicas e/ou com necessidades especiais, alimentação } \\
\text { especial, etc.) }\end{array}$ & & & & & & & $\begin{array}{l}\text { Gerente de Negócios; } \\
\text { Gerente de Hotelaria }\end{array}$ & & & & \\
\hline 1.5 .7 & Detalhes especiais de cordialidade no atendimento & & & & & & & $\begin{array}{c}\text { Diretor ADM Gerente } \\
\text { de Hotelaria }\end{array}$ & & & & \\
\hline 1.5 .8 & $\begin{array}{l}\text { Estabelecimento de critérios para qualificação dos } \\
\text { funcionários bi e trilingües }\end{array}$ & & & & & & & & & & & \\
\hline 1.5 .9 & $\begin{array}{l}\text { Estabelecimento de critérios para qualificação dos } \\
\text { funcionários que interagem com o público }\end{array}$ & & & & & & & $\mathrm{KH}$ & & & & \\
\hline $\begin{array}{c}1.5 .1 \\
0\end{array}$ & Treinamento e orientação do pessoal & & & & & & & $\begin{array}{c}\text { Diretor ADM Gerente } \\
\text { de Hotelaria }\end{array}$ & & & & \\
\hline $\begin{array}{c}1.5 .1 \\
1\end{array}$ & Presteza e cortesia & & & & & & & & & & & \\
\hline \multirow{3}{*}{$\begin{array}{c}1.5 .1 \\
2\end{array}$} & Serviço de despertador & & & & & & & & & & & \\
\hline & a) programável pelo próprio hóspede & & & & & & & \multirow{2}{*}{$\begin{array}{l}\text { Gerente de Recepção } \\
\text { Reservas, Gerente de } \\
\text { Hotelaria }\end{array}$} & & & & \\
\hline & b) executado pelo meio de hospedagem & & & & & & & & & & & \\
\hline $\begin{array}{c}1.5 .1 \\
3\end{array}$ & $\begin{array}{l}\text { Monitoramento das expectativas e impressões do } \\
\text { hóspede, incluindo meios para pesquisar opiniões, } \\
\text { reclamações e solucioná-las }\end{array}$ & & & & & & & $\begin{array}{l}\text { Comunicação/ } \\
\text { Ouvidoria }\end{array}$ & & & & \\
\hline
\end{tabular}




\begin{tabular}{|c|c|c|c|c|c|c|c|c|c|c|c|c|}
\hline \multirow{2}{*}{1} & \multirow{2}{*}{ ITENS GERAIS } & \multirow{2}{*}{ OBSERVAÇÕES } & \multicolumn{3}{|c|}{ CLASSIFICAÇAO } & \multirow{2}{*}{$\begin{array}{c}\text { ORIENTAÇÕES PARA O PLANO } \\
\text { DE AÇÃO } \\
\end{array}$} & \multirow{2}{*}{ Resp } & \multirow{2}{*}{$\begin{array}{l}\text { DEPARTAMENTOS } \\
\text { ENVOLVIDOS }\end{array}$} & \multicolumn{2}{|c|}{ Quando } & \multirow{2}{*}{$\begin{array}{l}\text { RESULTADO } \\
\text { AVALIAÇÃO FINAL }\end{array}$} & \multirow[t]{2}{*}{ OBS. } \\
\hline & & & NR & C & NC & & & & Início & Prazo & & \\
\hline $\begin{array}{c}1.5 .1 \\
4\end{array}$ & Identificação adequada para os fornecedores de serviços & & & & & & & $\begin{array}{l}\text { Gerente de Infra- } \\
\text { estrutura }\end{array}$ & & & & \\
\hline $\begin{array}{c}1.5 .1 \\
5\end{array}$ & $\begin{array}{c}\text { Apresentação, vestimenta e identificação adequadas para } \\
\text { os empregados }\end{array}$ & & & & & & & Governanta/ RH & & & & \\
\hline \multirow[b]{2}{*}{$\begin{array}{c}1.5 .1 \\
6\end{array}$} & Serviços de reserva: & & & & & & & & & & & \\
\hline & d) no período de 08 horas & & & & & & & $\begin{array}{l}\text { Gerente de Hotelaria/ } \\
\text { Supervisores }\end{array}$ & & & & \\
\hline 1.5 .1 & \multicolumn{6}{|c|}{ Serviços de recepcão: } & & & & & & \\
\hline $\begin{array}{c}1.5 .1 \\
8\end{array}$ & Serviços de mensageiro & & & & & & & Gerente de Hotelaria & & & & \\
\hline $\begin{array}{c}1.5 .2 \\
1\end{array}$ & Serviços de manutenção específico para HH. & & & & & & & $\begin{array}{c}\text { Gerente de Infra- } \\
\text { estrutura; Governanta; } \\
\text { Gerente de Hotelaria }\end{array}$ & & & & \\
\hline \multirow[b]{2}{*}{$\begin{array}{c}1.5 .2 \\
2\end{array}$} & Serviços de telefonia: & & & & & & & & & & & \\
\hline & b) com uma telefonista bilíngüe por turno & & & & & & & $\begin{array}{l}\text { Gerente de Hotelaria/ } \\
\text { supervisor de } \\
\text { Recepção }\end{array}$ & & & & \\
\hline 1.5 .23 & \begin{tabular}{|l|} 
Serviço de refeições leves e bebidas nas Unidades \\
Habitacionais ("room service") no período de 24 horas
\end{tabular} & & & & & & & & & & & \\
\hline $\begin{array}{c}1.5 .2 \\
4\end{array}$ & $\begin{array}{l}\text { Serviço de manobra e estacionamento de veículos por } \\
\text { funcionário habilitado no período de } 24 \text { horas }\end{array}$ & & & & & & & Gerente de Hotelaria & & & & \\
\hline
\end{tabular}

